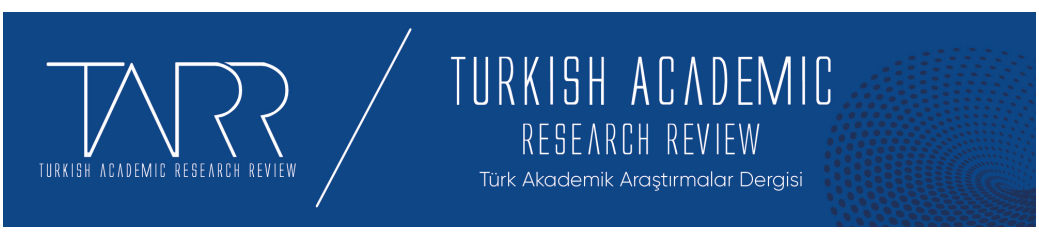

e-ISSN: 2602-2923 Yıl/Year: 2021 Cilt/Volume: 6 Sayı/Issue: 2

\title{
Değerler Eğitimi ve Batı Değerleri Üzerine Bir Analiz
}

\section{A Different Perspective On Values Education}

\section{Şakir GÖZÜTOK}

Prof. Dr., Van Yüzüncü Y1l Üniversitesi İlahiyat Fakültesi, Din Eğitimi Anabilim Dalı, Van Yuzuncu Yil University, Faculty of Theology Department of Religious Education, VanTurkey,sgozutok@yahoo.com, Orcid ID: 0000-0001-7232-6729

\begin{tabular}{r|l} 
Makale Bilgisi & Article Information \\
Makale Türü - Article Type & Araştırma Makalesi / Research Article \\
Geliş Tarihi - Date Received & 25 Mayıs / May 2021 \\
Kabul Tarihi - Date Accepted & 23 Haziran / June 2021 \\
Yayın Tarihi - Date Published & 25 Haziran / June 2021 \\
Yayın Sezonu & Nisan - Mayıs- Haziran \\
Pub Date Season & April - May - June
\end{tabular}

Atıf / Cite as: Gözütok, Ş. (2021). Değerler Eğitimi Ve Batı Değerleri Üzerine Bir Analiz/A Different Perspectıve On Values Educatıon. Turkish Academic Research $\begin{array}{lllll}\text { Review, } & 6 & \text { (2), } & 629-660 . & \text { Retrieved }\end{array}$ https://dergipark.org.tr/tr/pub/tarr/issue/62824/945398

Intihal / Plagiarism: Bu makale, en az iki hakem tarafından incelenmiş ve intihal içermediği teyit edilmiştir. / This article has been reviewed by at least two referees and confirmed to include no plagiarism. https://dergipark.org.tr/tr/pub/tarr

Copyright (C) Published by Mehmet ŞAHIN Since 2016- Akdeniz University, Faculty of Theology, Antalya, 07058 Turkey. All rights reserved.

Turkish Academic Research Review - Türk Akademik Araştırmalar Dergisi 


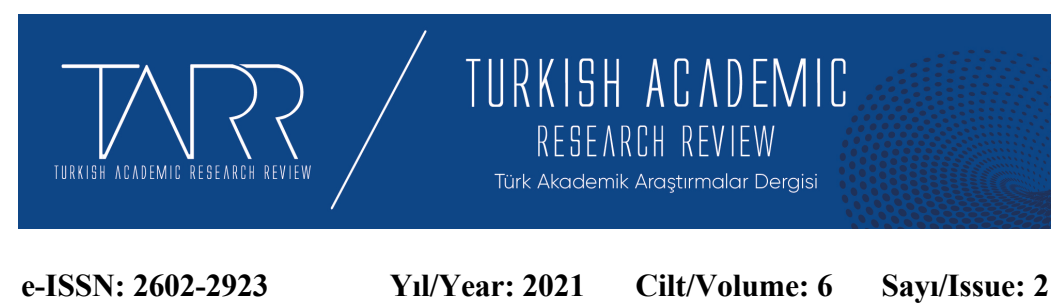

Değerler Eğitimi ve Batı Değerleri Üzerine Bir Analiz

\author{
Şakir GÖZÜTOK
}

$\ddot{O} \mathbf{z}$

Batı kültürünü Yunan felsefesi, Hıristiyan inancı ve Roma hukuku şekillendirir, bu münasebetle Batı değerleri de bu kültürün ürünüdür. Ancak Batı kültürünün ve buna bağlı olarak değerlerinin kırılma noktasını Fransız Devrimi oluşturmaktadır. Fransız Devrimi ile birlikte hem feodal yapı hem de kilise kaynaklı dinî anlayış geri plana itilmiştir. Artık Tanrı dogmalarının yerini insan almıştır. Rönesansla birlikte ferdiyetçiliğin öne çıktığı bir düşünce hakim olmuştur. Buna göre, toplumun değerlerinden çok ferdin değerleri önem kazanmıştır. Bu sebeple Batı değerleri, artık ferdin kıymet kazandığı değerler olmuştur. David Hume'un "Bütün dünyanın yıkılmasını parmağımın çizilip sıyrılmasına tercih etmek akla aykırı değildir" sözü bu dönemde ferdiyetçiliğin vardığı noktayı göstermesi bakımından ilginçtir. Rousseau ve Hegel'in ferdi değerlerini toplum ile buluşturma çabaları dikkat çekmektedir. Bilimin esas alınmasından sonra daha çok pozitif anlayışın belirlediği değerler öne çıkmaya başlamıştır. Buna paralel olarak dinî değerlerden soyutlanmış seküler değer yargısı esas alınmıştır. Ayrıca bu değerlerin Machiavelli ile birlikte demokrasiyi güçlendirmek amacına evrildiğini söylemeliyiz. Bilindiği gibi değerler kavramı, iktisat ilminden ödünç alınmıştır. Özellikle yirminci yüzyılın başlarında dile getirilen kavramlar, 1960'lardan sonra dikkat çekmişse de, esas olarak 1990'lı yıllardan sonra gereken ilgiyi görmüştür. Zira Batı toplumlarındaki her alandaki ahlâkî çöküntü değerleri yeniden ele almayı gerekli kılmıştır. Çok farklı bir yapıda olan Müslüman ülkelerde Batı değerlerinin olduğu gibi aktarılıp eğitiminin yapılması, bazı sorunlara sebep olmaktadır. Çünkü dinin beslediği İslamî değerlerin seküler değerler ile bağdaşması çok zordur. Her toplumun değerleri, onun yıllarca şekillenmiş kültürünün ürünüdür.

Anahtar kelimeler: Değerler, Değerler Eğitimi, Batı Değerleri, İslamî Değerler.

\title{
A Different Perspective On Values Education
}

\begin{abstract}
Western culture is shaped by Greek philosophy, Christian belief and Roman law, and in this context, Western values are also the product of this culture. However, the French Revolution constitutes the breaking point of Western culture and, accordingly, its values. With the French Revolution, both the feudal structure and the religious understanding originating from the church were pushed to the background. Now the dogma of God has been replaced by man. With the Renaissance, a thought in which individualism came to the fore prevailed. Accordingly, the values of the individual have become more important than the values of the society. For this reason, Western values have become the values that individuals are valued. David Hume's statement "It is not unreasonable to prefer the destruction of the whole world to scratching my finger" is interesting in terms of showing the point reached by individualism in this period. The efforts of Rousseau and Hegel to bring together individual values with the society draw attention. After
\end{abstract}

Turkish Academic Research Review - Türk Akademik Araştırmalar Dergisi 
taking science as a basis, the values determined by positive understanding started to come to the fore. Parallel to this, the secular value judgment abstracted from religious values was taken as a basis. We should also say that these values evolved with Machiavelli to strengthen democracy. As it is known, the concept of values has been borrowed from the science of economics. Although the concepts that were mentioned especially at the beginning of the twentieth century attracted attention after the 1960s, they received the necessary attention after the 1990s. Because the moral collapse in every field in Western societies has made it necessary to reconsider. In Muslim countries with a very different structure, the transfer of Western values and their education causes some problems. Because it is very difficult for Islamic values nurtured by religion to be compatible with secular values. The values of every society are the product of its culture that has been shaped over the years.

Keywoeds: Values, Values Education, Western Values, Islamic Values.

$$
\text { نظر مختتلف للتعليم القيم }
$$

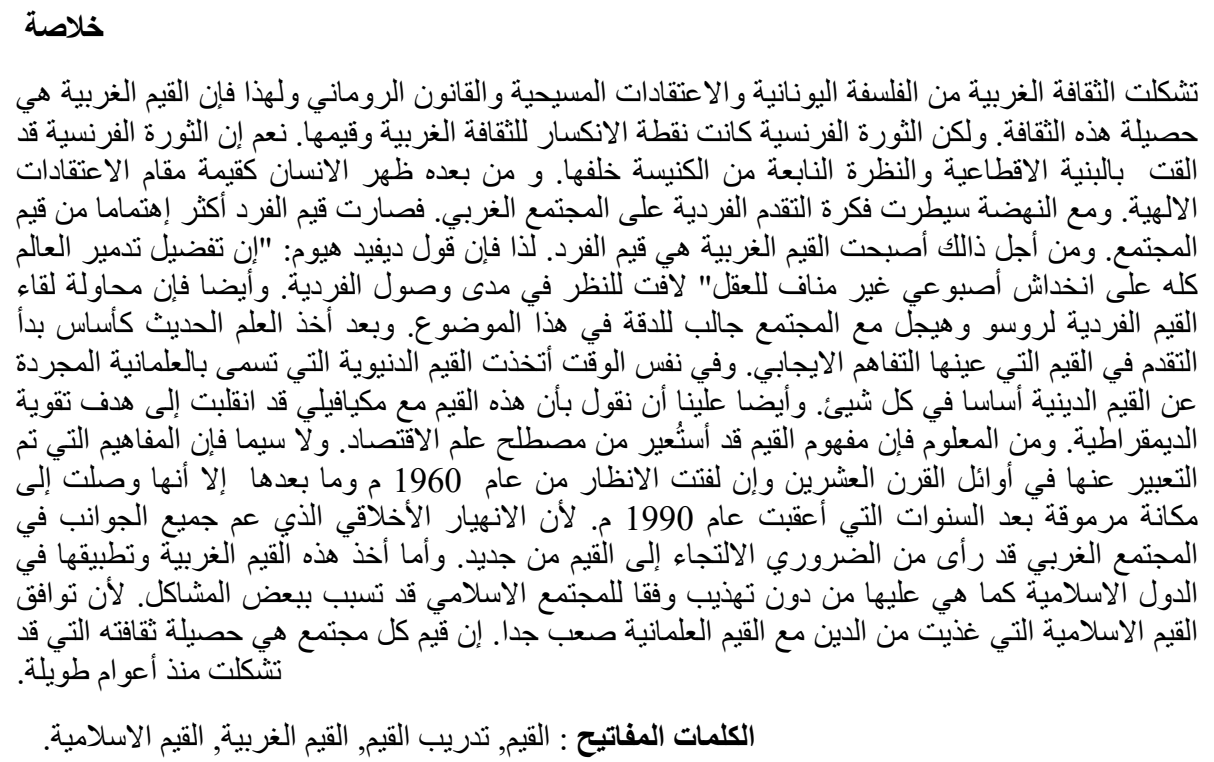

\section{Structured Abstract}

In this study, besides the general information about values education, we mainly tried to deal with the content and general characteristics of Western values. The concepts of "value" or "order of values" are two words that are new even in contemporary European languages. The word "valuer" in French meant "courage in battle" in its original use in Latin. Then, this word was used to mean the equivalent of something or a person until about one hundred and thirty years ago, then to mean price, expensive. It was later modified to mean the moral value something deserves or the symbolic appreciation we get. The use of this word in the sense of good, beautiful, true, to express moral value in the field of morality, appeared in French only in the second half of the nineteenth century. Halliday argues that the term "values" is in familiar use and has been the subject of many discourses since 1900, changing our understanding of objective values or virtues. Values today; are 
categorized as personal, social, societal and human values. Accordingly, the scope and meaning of values vary depending on time and generations. The fact that perversions, which were once considered a serious disease (for example, homosexuality), are presented as a social demand today also reveals how fluid and volatile values are in the modern era. So: 1- The sum of the meanings, values and rules that individuals or groups have creates their ideological culture. 2- The sum of their meaningful actions, in which values and rules emerge and take place, creates their behavioral culture. 3- The sum of all the other carriers, material, biological things and energies with which cultures are socialized constitutes their "material culture". We can summarize the main features of the understanding of basic values in the writings of many theorists and researchers as follows: Values are beliefs. But these are beliefs that are inextricably linked to feelings, not to objective, cold ideas. Values are a motivational construct. They refer to the desired goals that people are trying to achieve. Values transcend certain actions and situations. They are abstract goals. The abstract nature of values distinguishes them from concepts such as norms and attitudes that often refer to specific actions, objects or situations. Values guide the selection or evaluation of actions, policies, people and events. That is, values serve as standards or criteria. Values are ranked in order of importance relative to each other. People's values form an ordered "system of value priorities" that characterizes them as individuals. This hierarchical feature of values also distinguishes them from norms and attitudes.

As it is known, religions and moral systems contain values that they base themselves in their structures. With the French Revolution, there was a serious break in values in the West. While the bourgeoisie overthrew the castle, it also destroyed the church. With the Renaissance, there is a structure in which the individual stands out. In this period, David Hume will exaggerate individual values so much that he will even say, "It is not unreasonable to prefer the destruction of the whole world to the scratching of my finger." However, the fact that values came to the fore was not because values were considered important, but because they were needed. For this reason, values education could only come to the fore in the twentieth century. Because the moral collapse and the increase in crime rates in societies made it necessary. There are infrastructural elements that feed every civilization. Undoubtedly, Greek philosophy, Christian belief and Roman law constitute Western civilization. The cultural mix created by these three understandings has shaped the mind dagger of the Western world. There is no doubt that every culture has its own unique values that derive from its own society. Of course, seeing all Western values as one and the same can rightly cause criticism. Because values are, first of all, an information problem. Understandings that deal with knowledge in different forms will inevitably have different interpretations and perspectives on values.

Today, these prominent Western values also have some unique features. Western values are primarily individual. Martin Luther, who was angry that Christianity was completely surrendered to Aristotle's interpretations and that values and moral rules were formed by feeding on this understanding, referred to Aristotle as "that jester who led the Church astray". While much of his teaching had medieval Catholic antecedents, Luther was unique in his support of the absolute rights of worldly authority, and boasted of being unmatched. Herein lies Luther's significance for the history of moral theory. This surrender of the secular world to idiosyncratic apparatuses is further facilitated by Luther's doctrine of sin and justification. Thus, Luther puts the moral principles and values of the Christian sect he pioneered into action as an auxiliary device for secular understanding. Richard Sennett describes this detachment of the individual from the values of society as The fall of public man. The individualistic values that have matured in the West meet with the norms of society and try to be the voice of the general will, thanks to Jean-Jacques Rousseau's conscientious values that lead to the common good. Friedrich Hegel will

Turkish Academic Research Review - Türk Akademik Araştırmalar Dergisi 
also give shoulders to this understanding of Rousseau. Hegel, who has the delusion that there will be no philosophy after him, thinks that moral norms and values put the last point. Western values have been influenced by positivism. In particular, the realist understanding at the beginning and the positivist philosophy that developed accordingly, putting science at the center has also shaken the world of values and meaning to its roots. According to this, in order for something to enter the field of science, it must be subject to an objective approach, abstracted from values. However, values are the result of a subjective judgment, not an objective one. This naturally results in the discarding of values that were accepted in the past. Realists and the Positivists who came on the scene after them came to the conclusion that it was not possible to consider morality and science, which they accepted as a subjective phenomenon. In these periods, since "values" were not a stand-alone phenomenon, they were dealt with in moral principles and, in general terms, they appeared as moral values or moral judgments. However, when Agusut Comte, the head of the conciliatory positivists, had to preach some moral principles in the "religion of humanity" he was trying to reveal, he had to count morality as one of the sciences. We have to state that philosophers such as Morley, Durkheim and Spencer were particularly influenced by this understanding of Comte. Thus, positivists, who once did not take moral principles seriously, started to deal with this field in terms of revealing new values. Western values are non-religious and secular. The first requirement in values education in America today is that the values promoted are clearly secular and not religious in nature. Now the situation has come to such a point that talking about religion keeps people with a secular and secular mentality from sleeping. "God cannot speak of anything but Himself." This note by Léon Bloy on the Bible is an important half-truth. More recently Spengler; While he announces Decline of the West with a prophetic tone, he shows that the Western culture has entered the "civilization" process as the reason. According to him, this process of civilization emerges together with some negative developments in the moral field. These developments also show themselves as a corruption of some values and institutions of every high culture in the cultural period. Western values are to strengthen democracy. The association of certain values with democracy, which is the most ideal form of politics in the Western world, should be considered as a normal process in this respect. In that case, it is a natural result in terms of thoughts and values in the West that the most ideal values support democracy, which is the most ideal political regime. While the values that were previously put forward in the name of God were turned into an instrument of government in the name of God, now people were replacing God. Democracy, on the other hand, is based on the majority of people in order to reduce the error. Rousseau will say a little further: "The voice of the people is the voice of right." Now the sovereign must be people, not God. Because all people should have a right moral life, and they should also make a right choice.

Philosophy feeds the field of thought of the Western world, whereas in Muslim countries, thought and the values produced in relation to it originate from religious sources. Muhammed Draz expresses the fundamental differences of these two different structures with the following expressions: "The aim of philosophy is to think; its goal is rigid thought; comes to life before the eyes in a frozen state. The goal of religion is a spirit of vigor and breakthrough. Much of what philosophy reveals is theoretical; even in the practical part it is based on theory. The purpose of religion is practice; Even its theoretical side is based on practice." In this respect, the most predominant aspect of the religion of Islam, together with its theoretical aspect, is its practice, that is, its set of values. In this respect, the approach of Muslim society and Western societies to values fundamentally differs. In this respect, the transfer of Western values to other cultures will cause problems. Because of the close relationship between values and knowledge, values are always the product of a

Turkish Academic Research Review - Türk Akademik Araştırmalar Dergisi 
thought and belief. In this regard, values are the product of either a philosophical understanding or a belief. In some moral values, even if the trace of a belief or thought is not visible in the first place, it is not free from them due to the imposition of a culture that shapes the society from within. As the person appropriates the values fed from his own culture, he is faced with another "values" phenomenon with the values imposed on him by the society. However, the personal aspect of values gains an emotional meaning rather than information. Because most of the time, people's emotional worlds can get in front of their thoughts.

\section{Giriş}

$\mathrm{Bu}$ çalışmamızda ilk olarak değerler eğitimi ile ilgili genel bir bakıştan sonra Batı tarafından ortaya konulan değerlerin içeriği ele alınacak ve Batı kültüründen neşet eden değerlerin genel özellikleri belirtilmeye çalışılacaktır. $\mathrm{Bu}$ sebeple çalışmanın ana problemini, Batı değerlerinin temel özelliklerinin neler olduğu ve bu değerlerin diğer toplumlara uygulanıp uygulanamayacağı oluşturmaktadır. Zira Türkiye'de bazı araştırmacılar tarafından değerler eğitimi adına Batı dünyasından alınan değerlere bazı katkılar sunularak veya araya bir kısım fikirler serpiştirilerek, olduğu gibi toplumumuza uyarlanmak istenmektedir. Şüphesiz bu tutumun doğru olup olmadığı da tartışmayı hak etmektedir.

Batı dünyasında özellikle de Fransız İhtilali ciddi bir kültürel kırılma ve buna bağlı olarak değerlerin inkırazına sebep olmuştur. Zira bu ihtilal yalnızca krala karşı gerçekleştirilmiş bir ayaklanma değildi, kral ile birlikte dini temsil eden kilise de yıkılmıştır. Beraberce cenazeleri omuzlanan krallığın ve papazların bu hazin sonu, şu özdeyişle ifade edildi: "Son kralı, son papanın bağırsakları ile bağladılar."1 Cemil Meriç'in de işaret ettiği gibi Fransız devriminden sonra burjuvazi, kavga arkadaşlarını ziyafet sofrasından kovar. İnsanlar eşittir ama sadece kanun karşısında. Kanunun yapan ise yine burjuvazidir. Ne var ki, burjuvazi şatoyu devirirken kiliseyi de yıkmıştır. ${ }^{2}$

Hıristiyanlığın barışa, değişime karşı direnişi ve bağnazlığa kayışı karşısında insanı merkeze alan "hümanist” anlayış, Batı kültürünün hamurunda bir müddet önce yoğrulmaya başlanmıştı. Bu anlayışın, insana yaptığı vurgu çok belirgindir. Artık Tanrı ve kilise dogmalarının yerine "insan" geçmektedir. Böylece Rönesans ile birlikte geleneksel otoritenin yerini ferdiyetçiliği esas alan liberal bir yaklaşım

${ }^{1}$ Hasan Hanefi, Muhammed Abid el-Cabiri, "Laiklik ve İslâm”, İslâmi Araştırmalar Dergisi, 8/3-4 (1995), 160.

${ }^{2}$ Cemil Meriç, Mağaradakiler (İstanbul: Ötüken Yayınları, 1978), 30, 31.

Turkish Academic Research Review - Türk Akademik Araştırmalar Dergisi 
almaya başlamıştır. ${ }^{3}$ Rönesans ile birlikte yanmaya başlayan liberalizm ve ferdiyetçilik meşalesi, yüzyılları aydınlatacak bir ışıktı ve üç sütun üzerinde yükseliyordu: Hürriyet, akıl ve fert.

Böylece ferdin öne çıktığı bir bürokratik yapılanma zuhur etmiştir. David Hume, bu dönemde öne çıkan ferdi değerleri o kadar abartacaktır ki, "Bütün dünyanın yıkılmasını parmağımın çizilip sıyrılmasına tercih etmek akla aykırı değildir" bile diyecektir ve bunu şöyle temellendirecektir: Çünkü akıl herhangi bir anlamda tutkular arasında hüküm ve karar verme yetkisine sahip olamaz. "Akıl, yalnızca tutkuların kölesidir ve kölesi olmalıdır ve asla tutkulara hizmet ve itaat etmekten başka herhangi bir vazife üstlenmiş tavrı takınamaz." "4 Aynı şekilde Hobbes da, insanları, "toplumsal temas kazası" sayesinde yalnızca olumlu tarzda toplumsal varlıklar olarak resmedecektir. ${ }^{5}$ Ama unutulan birşey var ki toplumun ferde kendi kültürüne bağlı bir özgürlük alanı bağışladığıdır. Bu özgürlük alanı da, toplumun değer yargılarının benimsenmesi oranında genişleyip daralmaktadır.

Bilindiği gibi değer kavramı iktisattan ödünç alınmıştır. Ne var ki iktisatta eyşaya karşı kullanılmakla birlikte, sosyal ilimlerde değerle birlikte söz konusu olan insandır. Değerlerin en yalın şekilde dile gelişi bireylerin ya da grupların tercihte bulundukları yargılarda, iyi/kötünün, doğru/yanlışın, sevilen/sevilmeyenin ne olduğuna ilişkin görüşlerinde ortaya çıkar. Tıpkı inançlar gibi değerler de, bir sistem içerisinde ifade edilir. Ancak değer sistemleri, deneysel inançların sisteminden farklıdır. Kabaca bir ayırıma gidecek olursak, birisi dünyaya ilişkin şeylerin doğru olup olmadığını belirleme iddiasındayken, diğeri şeylerin tercih edilebilir olup olmadıklarını belirleme iddiasındadır. Bundan dolayı değerler, inançların ortaya çıkardığı şeylere ilişkin eylemi gerektirirler. John Dewey bu gibi iddiaları ve eylemleri, “etmenler” olarak tanımlıyordu. Böyle bakınca değerler dünyası özerk ve anlaşılmaz değildir. İnançla pratik arasında bir geçiş bölgesidir. Günümüzde ise değerler daha çok çıkarlardır. ${ }^{6}$

Allport, Vernon ve Lindzey, değerleri gazete okumak, film izlemek veya oy vermek gibi sıradan faaliyetlerle ilişkilendirerek değer kavramına daha somut, dünyevî bir anlam veren ilk sosyal bilimcilerdendi. Bu yazarlar, kişilerin her tür özel ve toplumsal davranışa yönelik istikrarlı tercihlerinin kategorize edildiği bir değerler

\footnotetext{
${ }^{3}$ Kemal Aytaç, Avrupa eğitim tarihi (İstanbul: M.Ü. İlâhiyat Fakültesi. Yayınları, 1992), 100.

${ }^{4}$ David Hume, A Treatise of human nature (London: Logmans Green and Co., 1898), 195, 196.

${ }^{5}$ Alasdair Maclntyre, Homerik çağdan yirminci yüzyıla etik'in kısa tarihi, trc. Hakkı Hünler, Solmaz Zelyüt (İstanbul: Hünler, Paradigma Yayınları, 2001), 212.

6 J. M. Blaut, Sömürgeciliğin dünya modeli, trc. Serbun Behçet (İstanbul: Dergâh Yayınları, 2015), 69 .
} 
tipolojisi tasarladılar. Bununla birlikte, sabit değerlerin ayrı ve sabit unsurlar olarak olduğu bir tipoloji fikri, her bireyin kültürde mevcut olan değerlerden çok, kişisel ve esnek bir hiyerarşi yarattığı fikri lehine yavaş yavaş terk edilmiştir. Şu anda değerler, belirli durumları aşan, zamanla değişebilen, davranış ve olayların seçimine rehberlik eden ve doğasında çelişkiler içeren dinamik bir sistemin parçası olan yaşamda yol gösterici ilkeler olarak düşünülmektedir. ${ }^{7}$

Hayatın yol gösterici ilkeleri olarak benimsenen değerlerin, öne çıkması biraz da belli ihtiyaçlardan kaynaklanmaktadır. Bazı araştırmacıların da işaret ettikleri gibi günümüzde değerlere bu denli yapılan vurgu, değerlere verilen önemin artmasından değil, onlara olan ihtiyacın $\operatorname{artması}^{8}$ da anlamına gelmektedir. $O$ halde gözden kaçırılmayacak bir ayrıntı var ki o da, Batı değerlerinin her ne kadar toplumsal bir ihtiyaçtan ele alınıyorsa da, ileride de açılayacağımız gibi, kişisel bir zeminden hareketle oluşturulduğu ve ferdî değerlere dayandığıdır. Bununla beraber bu değerlerin taşıdığı diğer özellikleri ağaşıda ele alacağız. Ama öncelikle değer kavramı ve kapsamını ele almakta fayda vardır.

\section{Değerlerin Tanımı}

Değerlerin tanımı üzerine birçok şey yazılmıştır. Değerler, özel ve kamusal yaşamın tüm alanlarında karar verirken insanların önemli olduğuna inandıkları şeylerin temelini oluşturan yol gösterici ilkelerdir. İnsanların bir yargıya varırken neye öncelik vereceğini ve gelişme arayışında ne için çaba göstereceklerini belirler. ${ }^{9}$ Goerg Simmel'in yaptığı şu açıklama, değeri daha iyi anlamamıza yarayacaktır: "Hayatlarımız her ne kadar şeylerin mekanizmaları ve nesnelliği tarafından belirleniyormuş gibi görünüyorsa da, aslında şeylere duygularımız üzerinden değerler yüklemeksizin ve onları eylemlerimizle bağlantılı olarak yönlendirmeksizin, ne bir adım atabiliriz ne de herhangi bir şey düşünebiliriz."10

Çok iyi biliniyor ki günümüzde kullandığımız haliyle "değer" veya "değerler düzeni" kavramları, çağdaş Avrupa dillerinde bile yeni olan iki kelimedir. Fransızcadaki "valuer" (değer) kelimesi, Latince aslındaki kullanılışında "savaşta gösterilen cesaret” anlamına gelmekteydi. Sonra bu kelime, yaklaşık yüz otuz yıl

7 Debats, D.L. \& Bartelds, B.F. The structure of human values: a principal components analysis of the Roheach Value Survey (RVS), Debats, D. L. H. M, Meaning in life: psychometric, clinical and phenomenological aspects (1996), 47, 48.

${ }^{8}$ Z. Şeyma Aslan, Fatma T. Yaşar, "Yükselen değer kavramı üzerine eleştirel bir yaklaşım”, Değerler Ĕgitimi Dergisi, 1 (2007), 10, 11.

9 OECD, Future of education and skills 2030 concept (2019), 4.

10 Georg Simmel, Bireysellik ve kültür, trc. Tuncay Birkan, (İstanbul: Metis Yayınları, 2009), 68

Turkish Academic Research Review - Türk Akademik Araştırmalar Dergisi 
öncesine kadar bir şeyin ya da bir kişinin dengi anlamına, sonra fiyat, paha anlamına kullanılıyordu. Daha sonra bir şeyin hak ettiği manevi kıymet ya da elde ettiğimiz sembolik takdir anlamına gelecek şekilde değişikliklere uğradı. ${ }^{11} \mathrm{Bu}$ kelimenin ahlâk alanında ahlâkî değer ifade edecek biçimde iyi, güzel, gerçek anlamlarındaki kullanımı ise, Fransızca'da ancak on dokuzuncu yüzyılın ikinci yarısında ortaya çıkmışır. ${ }^{12}$ Halliday, "değerler" teriminin tanıdık bir şekilde kullanıldığını ve 1900 'den beri pek çok söyleme konu edildiğini, nesnel değerler veya erdemler hakkındaki anlayışımızı değiştirdiğini savunmaktadır. Heenan'a göre değerler, herhangi bir birey, grup veya toplumun herhangi bir nedenle tercih ettikleridir. Öteden beri böyle bilinmekle beraber, eski değerlerin yapısı bozuldu ve kişiselleştirilen değerler haline getirildi. Bununla birlikte, herhangi bir değer listesi muhtemelen bir zamanlar erdem olarak kabul edilenleri içermekteydi. Değerler, öznelerin "sahip olmayı" arzuladıkları tercihlerden "olmayı arzulayan” ilkelere kadar geniş bir yelpazede var olabilir. ${ }^{13}$

$\mathrm{Bu}$ bağlamda $\mathrm{OECD}$, yerel durumları da gözönüne alarak değerleri dört kategoride ele almaktadır:

- Birincisi kişisel değerlerdir. Kişinin, fert olarak kim olduğu ve anlamlı bir yaşamı nasıl tanımlayıp sürdürmek ve hedeflerine ulaşmak istediği ile ilişkilidir.

- İkincisi sosyal değerlerdir. Kişilerarası ilişkilerin kalitesini etkileyen ilke ve inançlarla ilgilidir. Birinin, başkalarına nasıl davrandığını ve çatışmalar dahil olmak üzere etkileşimleri nasıl yönettiğini içerir. Sosyal değerler aynı zamanda sosyal refahla ilgili kültürel varsayımları da yansıtır, yani bir topluluğu ve toplumu etkili bir şekilde çalıştıran şeylerdir.

- Üçüncüsü toplumsal değerlerdir. Kültürlerin ve toplumların önceliklerini, sosyal düzeni ve kurumsal yaşamı çerçeveleyen ortak ilkeleri ve yönergeleri tanımlar. Bu değerler, sosyal ve kurumsal yapılarda, belgelerde ve demokratik uygulamada yüceltildiklerinde ve kamuoyu aracılığıyla onaylandıklarında var olurlar.

- Dördüncüsü ise insanî değerlerdir. İnsanî değerlerin toplumsal değerlerle pek çok ortak noktası vardır. Ancak insanı aşan, uluslar ve kültürler olarak tanımlanırlar. Bu değerler, insanlığın refahı için geçerlidir. Genellikle "İnsan Hakları

${ }^{11}$ J. R. V. Marghant \& Josep F. Harles, Latin dictionary (London: Gassell nad Company, ts.), 606; Kelsey Harbert, History of teaching and the value agenda, PHD thesis (Austuralia: James Cook University, 20009), 35.

12 Muhammed Abid el-Cabirî, Arap ahlâki aklı, trc. Muhammed Çelik (İstanbul: Mana Yayınları, 2015), 66, 67.

${ }^{13}$ Harbert, History of teaching, 35. 
Evrensel Beyannamesi" ve "Birleşmiş Milletler Sürdürülebilir Kalkınma Hedefleri” gibi uluslararası kabul görmüş sözleşmelerde ifade edilirler. ${ }^{14}$

$\mathrm{Bu}$ değerler gözönüne alındığında, ülkemizde zaman zaman çeşitli değerlere atıf yapılsa da yerel değerlerden çok toplumsal değerler öne çıkarılmaktadır. Okullarımızda öğretilmesi istenen değerler de, bu münsabetle toplumda barışı sağlamaya yönelik değerlerin eğitimidir.

Bilindiği gibi düşünce yapısının değişmesi beraberinde değerler dünyasının da farklılaşmasına sebep olabilmektedir. İlahî bir kaynağa dayanan inanç ve düşüncelere göre değerlerin önemli bir kısmını, insanlar değil kendilerine yön veren inançlar belirlemektedir. Ancak zamanla bireyselciliğin ve buna bağlı olarak insan hürriyetine yapılan vurgunun artması, değerler dahil insanı ilgilendiren her alanın yine insan tarafından belirlenmesi gerektiği fikrini öne çıkarmıştır. Buna bağlı olarak değerlerin kapsamı ve anlamı, zamana ve nesillere bağlı olarak değişiklik göstermektedir. Bir zamanlar ciddi bir hastalık olarak kabul edilen (mesela eşcinsellik) sapkınlıkların, günümüzde birer sosyal talep olarak sunulması da, değerlerin modern dönemde ne kadar seyyal ve değişken olduğunu ortaya koymaktadır.

O halde: 1- Bireylerin ya da grupların sahip oldukları anlamların, değerlerin, kuralların toplamı, onların ideolojik kültürlerini meydana getirir. 2- Değerlerin ve kuralların belirdiği ve gerçekleştiği anlamlı eylemlerinin toplamı, onların davranışsal kültürlerini meydana getirir. 3- Kültürlerin toplumsallaştığı bütün öteki taşıyıcıların, maddi, biyolojik şeylerin ve enerjilerin toplamı, onların "maddi kültür"lerini meydana getirir. Böylece, bir kimse ya da grubun toplam ampirik kültürü bu üç kültür düzeyinden oluşmaktadır. Yani ideolojik, davranışsal ve maddi. ${ }^{15} \mathrm{Bu}$ üç kültür düzeyi, hem ferdin hem de toplumun değerlerinin bütünlüğünü ortaya koymaktadır.

\section{Değerler ve Kapsamı}

Değerlerin eğitiminde öncelikle kavramsal çözümleme yapmak, onları daha iyi anlamamız ve olgularla ilgisini kurmamız açısından önemlidir. Değerlerin kavram olarak çözümlenmesi, onların mantıksal ölçülere sokulması demektir. Sosyal bilimciler buna "value-neutral" demektedirler. Bu teknik bir yöntem olup, bir tür kavram çözümlemesidir. Sosyal bilimciler bu tekniği daha nesnel sonuçlar elde

${ }^{14} \mathrm{OECD}$, Future of education and skills, 4.

15 Pitirim A. Sorokin, Bir bunalım çağında toplum felsefeleri, trc. Mete Tuncay (İstanbul: Göçebe Yayınları, 1997), 234.

Turkish Academic Research Review - Türk Akademik Araştırmalar Dergisi 
etmek için kullanırlar. Bu tür bir çözümleme, eğitim sisteminde programlar hazırlanırken gözönünde bulundurulması gereken çözümlemelerdir. ${ }^{16} \mathrm{Bu}$ münasebetle biz de öncelikle değerler kavramının çözümlemesiyle işe başlamalıyız.

Bazı araştırmacılara göre "değer hükmü”, birşeyin arzu edilebilir veya edilemez olduğunu belirten ifadedir. Şayet böyle ise, o halde "değer" de, birşeyin arzu edilebilir veya edilemez olduğu hakkındaki inançtır. Fakat değer acaba sadece bir inançtan, yani sübjektif bir yakıştırmadan mı ibarettir? Bizim inancımız dışında objektif bir gerçeği temsil etmez mi? İşte ahlâk felsefesinin en eski, en çözülmez görünen problemlerinden biri budur. ${ }^{17}$ Her ne kadar günümüzde değerler müstakil bir konu olarak ele alınmakta, incelenmekte ve değerlendirilmekte ise de, biraz geriye doğru gittiğimizde yukarıdaki değerlendirmelerden dolayı değerlerin, ahlâkî felsefesinin konuları içerisinde işlendiği görülecektir. Çünkü değerlerin ahlâk ile sıkı bir ilişkisi vardır. Bu sıkı ilişki, ahlâkî kuralların olgusal önermeler içermesinden kaynaklanır. $\mathrm{Bu}$ münasebetle ahlâk (etik) ise, felsefe ile birlikte konuşulmuş ve tartışılmıştır. Aritotales'in Ethika'sında çok beligin olarak öne çıkmasa da (çünkü o, iyi olanı ve mutluluğu politika ile birlikte mümkün görüyordu, bu yüzden Ethika'nın konusu politikaydı), o zamandan bu yana ahlâkın ortaya koyduğu iyi ve kötü hükmü, aynı zamanda değerlerle de ilişkilidir. Zira iyi olan methedilir ve kötü olan da yerilir.

Değer, kişiler ve kişilerin toplumla olan sosyal münasebetlerinde ortaya çıkmaktadır. Yapılan araştırmalarda karıncalar ve arıların da sosyal örgütlenme düzeyinde olduklarını ortaya koymuştur, ancak onlarda insanlardaki gibi bir kültürden söz etmek mümkün olmadığından herhangi bir değerden veya değer yargısından söz edemeyiz. Zira insanlardaki “toplumsal kültürü” ortaya koyan görüşler, değerler ve algılardır. Çünkü değerler, sosyal ilişkileri belirleyen normlar ve kalıplardır. Sartre'nin dediği gibi “toplumun değerler düzeni onun yapısını yansıtır." Bunun tersi de doğrudur. Değerler basamağı (veya değerler düzeni), bireyin ürettikleri olsa da, daha çok toplum içindeki grupların veya toplumun tamamının ürünüdür. ${ }^{18}$ Kabul edilen bir değeri, "nasıl kullanacağım?” sorusu bizi ahlâk ile birlikte eğitimle; “onu nasıl anlayacağım?” sorusu ise felsefeyle buluşturur. Eğitim bir değerin hem nasıl olduğunu hem de nasıl ortaya çıktığı ile ilgilendiği gibi, nasıl uygulanması gerektiğini de konu edinir.

16 İhsan Turgut, Eğitim üzerine felsefi bir deneme (İzmir: Bilgehan Matbaası, 1991), 8.

17 Erol Güngör, Değerler psikolojisi üzerinde araştırmalar (İstanbul: Ötüken Yayınları, 1998), 27.

${ }^{18}$ Cabirî, Arap ahlâki aklı, 66, 67. 
Değerlerimizi düşündüğümüzde, hayatımızda bizim için neyin önemli olduğunu düşünürüz (örneğin, güvenlik, bağımsızlık, bilgelik, başarı, nezaket, zevk vs). Her birimiz, değişen derecelerde önem taşıyan çok sayıda değere sahibiz. Belirli bir değer bir kişi için çok önemli, ancak bir başkası için önemsiz olabilir. Temel değerleri kavramsallaştırmanın en yararlı yolu ile ilgili fikir birliği 1950'li yıllardan beri yavaş yavaş ortaya çıkmıştır. Pek çok kuramcı ve araştırmacının yazılarında yer alan temel değerler anlayışının esas özelliklerini şu şekilde özetleyebiliriz:

- Değerler inançlardır. Ancak bunlar nesnel, soğuk fikirlere değil, ayrılmaz bir şekilde duygulara bağlı inançlardır.

- Değerler motivasyonel bir yapıdır. İnsanların ulaşmaya çalıştıkları arzu edilen hedeflere atıfta bulunurlar.

- Değerler belirli eylemleri ve durumları aşar. Soyut hedeflerdir. Değerlerin soyut doğası, onları genellikle belirli eylemlere, nesnelere veya durumlara atıfta bulunan normlar ve tutumlar gibi kavramlardan ayırır.

- Değerler, eylemlerin, politikaların, kişilerin ve olayların seçimine veya değerlendirilmesine rehberlik eder. Yani değerler standart veya kriter olarak hizmet eder.

- Değerler, birbirlerine göre önem sırasına göre sıralanır. İnsanların değerleri, onları bireyler olarak nitelendiren sıralı bir "değer öncelikleri sistemini” oluşturur. Değerlerin bu hiyerarşik özelliği aynı zamanda onları normlardan ve tutumlardan da ayırır. ${ }^{19}$

Yukarıda da ifade ettiğimiz gibi değerler, insanın kendi davranışı ile toplumla ilişkisinde ortaya çıkmaktadır. Bu sebeple davranışı inceleyeceksek, onu her iki yönde de izlemeliyiz: Hem tek başına bir toplumu bir arada tutan insanların görevleri hem de toplumun kişilere izin vermesi gereken hareket özgürlüğü açısından bakılmalıdır. Mesele, bu ikilemde ortaya çıkan bir ortak alanda zuhur ediyorsa, o zaman değerler sorunu, yalnızca bireylerin, "özgür insan olma" ihtiyaçları ile "sosyalleşme" ihtiyaçlarını bir araya getirmeye çalıştıklarında ortaya çıkmaktadır. Her iki ihtiyacı da kabul etmeyen bir felsefe, değerleri geliştiremez ve aslinda onlara izin de veremez. ${ }^{20}$

\section{Değerler Eğitimi}

19 Shalom H. Schwartz, "Basic human values: An overview", https://www.researchgate.net/publication/237364051 (17.02.2021).

20 J. Bronowski, Science and human values (New York: Julian Messner Inc., 1956), 70.

Turkish Academic Research Review - Türk Akademik Araştırmalar Dergisi https://dergipark.org.tr/tr/pub/tarr 
Asırlar boyunca ilmle birlikte hikmet ve hakikat arayıcıları, ilmin en ulvi gayesinin Yaratıcıyı ve dünyayı kendini-anlama ve kendini-gerçekleştirme yoluyla doğru bir şekilde idrak etmek olduğunu anlamışlardı. Çok geçmeden bu yaklaşım, en sonunda terk edildi ve neredeyse tamamen başka bir görüş ile değiştirildi. Bilim aslen bir kontrol ve manipülasyon aracı olarak anlaşılmaya başlandı. Hiç şüphesiz, birçok bilim adamı ahlâklı ve faziletli insanlar olmayı sürdürdüler, ancak bunun yanında dünyanın tabiatına dair ilmî arayışlarıyla bağlantılı olarak erdemin hakikatte ne için gerekli olduğu sorusuna muhatap olmamaya başladılar. Pierre Hadot'un işaret ettiği gibi, felsefe her zaman bir hayat tarzı ve manevi ilim olagelmişti. Nihayet enfüsî daireye dair kaygılar, din âlimleri ve ahlâkçıların şahsi meselesi haline indirgendi. Ahlâkbilim "hakiki" ilme sonradan eklenmiş bir düşünceymiş gibi gösterilmeye başland1. Modern öncesi gelenekler ilmi, nefsi terbiye etmek ve kemale erdirmek için aramışlardı, ancak modern bilimsel teşebbüsler nefsi sübjektif âleminde kendi haline bıraktı. Bütün bu olup biteni Bryan Appleyard haricindeki çok az kimse ortaya koydu. Appleyard, bazı neticelere varırken şunu diyordu: "Hoşgörü ve hoşgörü eğitimi diğer Avrupa ülkelerinde olduğu gibi Almanya kamuoyunun da başlıca meselesi olmuştur. En son İngiltere olmak üzere İspanyayı içine alan birçok Batı ülkesindeki terörist saldırıların sonucu olarak ve Almanya'da mültecilere karşı yapılan açık şiddet olaylarından sonra birçok politikacı ve eğitimci hoşgörü eğitimine ciddi bir ihtiyacın olduğunu fark ettiler.”21

En çok hoşgörünün öne çıkarıldığı değer olması, ona en çok ihtiytaç duyulmasındandır. Bilindiği gibi değerler eğitiminin telafuz edilmesi, programlara alınması ve uygulanması, çok eskilere kadar gitmez. Batı toplumlarının, Fransız İhtilali'nden sonraki değerler alanındaki yıkımı görebilmesi için en az üç asrın geçmesi gerekecekti. Çünkü bir toplumun öteden beri gelenek haline getirdiği değerleri, birden bire ortadan kaldıralamaz. Bunların izleri nesiller boyunca devam eder. Ancak eskiden beri toplumların kabul ettiği değerlerin "bilimsel değerler"e kurban edilmesinin getirdiği sıkıntı son çağda ciddi bir şekilde hissedilmiştir. Bundan hareketle "Değerler Eğitimi”nin ilk kez telafuz edilmesi ve ortaya çıkışı, 1920'lerde Amerika'da karakter eğitimi alanındaki ilk çalışmalara dayanmaktadır. Zira değerler gerçekte karakterimizi oluşturan ögelerin birer parçasıdır. Bu gecikmenin sebebi, Rönesans döneminde eğitim tartışmalarını büyük ölçüde etkileyen dikkat çekici olgu, öznelciliğin (subjectivism) ortaya çıkmasıydı. Örneğin, ortaçağ "vergiler/harçlar" dan türetilen "karakter" terimi, 12. yüzyılda ahlâkı ifade

21 Friedrich Schweitzer, "Dini Bireyleşme: Hoşgörü Eğitimine Karş1 Yeniden Meydan Okumalar”, Sakarya Üniversitesi İlahiyat Fakültesi Dergisi, 16 (2007), 164. 
eden bireysel özellik ile ilişkilendirilmeye başlanmıştı. Böylece, Rönesanstaki gelişmeler, dinî ve seküler motiflere dayalı değer eğitimi için teorik ütopyayı başlatmış oluyordu. Değerin ahlâkla ve dolayısıyla karakter ile ilişkilendirilmesi bu tarihi arka plana dayanmaktadır.

On dokuzuncu yüzyılda, değerler ve etik hala Amerika'daki okul müfredatının bir parçasıydı, açık ve doğrudan bir şekilde öğretiliyorlardı. Belki de en popüler okuma metni olan McGuffey'in okuyucuları, dürüstlük, sıkı çalışma ve tasarruf gibi değerleri yüceltiyorlardı. Danbury Babtits Association'a 1802'de yazdığı bir mektupta Thomas Jefferson, "kilise ile devlet arasındaki ayrılık duvarı" olduğunu ortaya koydu. Amerika'da dini ilerletmeden kişinin ahlâkı öğretebileceği anayasal inancını yansitıyordu. Ancak on dokuzuncu yüzyılda, Jefferson'un "duvarı" bazen öğrencilere ahlâk ve değerleri öğretmek isteyenler tarafindan aşıldı. Örneğin, Massachusetts eğitim kurulu sekreteri Horace Mann, o eyaletteki devlet okulu öğretmenlerinin her okula İncil'in King James Versiyonundan on ayeti "yorum yapmadan" okuyarak başlamasını istedi. Mann, Amerika Birleşik Devletleri genelinde yaygın olarak takip edilen uygulamanın, öğrencilerin "akıl ve vicdan" geliştirmelerine yardımcı olmanın bir yolu olduğuna inanıyordu. İncil okumayı destekleyen Mann gibiler, bu şekilde öğretilen ahlâkî değerlerin hem evrensel hem de mezhepsel olmadığı inanciyla bunu yaptılar. ${ }^{22}$

Nedense Amerika'da1930'lara gelindiğinde karakter eğitimine olan ilgi azaldı ve bu durum 1960'l yılların ikinci yarısına kadar devam etti. Değerler eğitimi ile ilgili çalışmalar 1970'lerin ortalarından itibaren yayınlanmaktadır. Amerika'da değerler eğitimi üzerine yapılan bu çalışmalar incelendiğinde Rokeach, Simon, How, Raths, Harmin, Kirschenbaum, Kohlberg gibi isimler öne çıkmaktadır. 1980'lerde değerler eğitiminin durgunluktan geçtiği açıkça görülmektedir. 1990'lı y1llarda sosyal ve manevi değerlere verilen önem azalırken, bireysel uyum değerleri öne çıktı. Aratık son dönemlerde sosyal anlamda bir çöküşü işaret eden gelişmeler (gençlerin cinsel bağımlılığı, madde kullanımı, erken gebelik, intiharlar, artan boşanma oranları vb.) sorunlarla baş edilemeyince, değerler ve ahlâkî eğitimi yeniden gündeme getirdi. Aileler, eğitimciler ve toplum liderleri, bu olumsuz gelişmeler karşısında okullarda ahlâk ve değer eğitimine ağılık vermeye

${ }^{22}$ Kristen J. Amundson, Teaching values and ethics an AASA critical issues report problems and solutions (Arlington: American Association of School Administrators Library and Congress, 1991), 18.

Turkish Academic Research Review - Türk Akademik Araştırmalar Dergisi https://dergipark.org.tr/tr/pub/tarr 
başlamışlardır. ${ }^{23} 2000^{\prime} l i$ yıllardan itibaren bu gelişmelere paralel olarak değerler eğitimi ile ilgili çalışmalar hız kazanmıştır. Bu çerçevede değerler eğitimiyle ilgili kitap, dergi ve uluslararası sempozyum sayısında göze çarpar şekilde artış olmuştur. ${ }^{24}$ Çoğu meselelerde olduğu gibi bu konunun da ülkemizdeki yansımasını görebilmek için fazla beklemeye lüzum yoktu.

Hofstede, Hofstede ve Minkov'un (2010) işaret ettikleri gibi, değerlerimizin önemli bir bölümü, aile içinde yetiştirilme yoluyla öğrenilir. Genel anlamda, aile Avrupalılar için çok önemli görünmektedir. Ülkeler arasındaki farklar küçüktür ve haritalar, bu konuda yanlış bir izlenim uyandırabilir. Aile önemlidir, ancak aile kavramından ne anlaşıldığ farklılık gösterebilir. ${ }^{25}$ Çünkü her toplumun aileye biçtiği rol değişiktir. Aile yapısının güçlü olduğu toplumlarda değerler eğitiminin önemli bir kısmının ailede verilmesi beklenir.

M. Rokeach tutumun bir inançlar organizasyonu olduğunu, değerin ise tek bir inanca işaret ettiğini iddia etmektedir. Rokeach tutumla değeri ayırdetmek üzere bunlar arasında yedi fark saymaktadır. Bu farklardan en önemli görüneni, yukarıda belirtildiği gibi, değerin tek bir inanca işaret etmesine karşıllk tutumun birçok inançtan teşekkül ettiği iddiasıdır. ${ }^{26}$ Oysa Dewey ve Kohlberg değerleri öğretme yöntemlerinin ortak noktası, okulların herhangi bir değeri doğrudan telkin etmemesiydi. Her iki yaklaşım da ahlâki muhakeme ve karar verme becerilerini geliştirmek için öğrencilerin anlık deneyimlerine dayanıyordu. Her ikisi de dinin okullarda tartışmaya uygun olmadığını, özel bir mesele olduğunu varsayıyordu. Birçok ebeveyn ve eğitimci, özellikle değerlerin netleştirilmesinin öğrencilerde ahlâkî görecelik gelişimini desteklediğine inanıyordu. ${ }^{27} \mathrm{Bu}$ yaklaşımı, modern çağın geliştirdiği ve teknoloji ile beslenen medya da destekliyordu.

Garaudy, bu gelişmelerin neticesini şöyle özetliyordu:

"Sadece basın, reklam, radyo, televizyon, sinema gibi kültürü kitlelere ileten araçların mutlak gücü değil, aynı zamanda bunları, bireylerin davranışlarını iktisadî, ahlâkî, siyasî maksatlarla şartlandırmak için kullanılan kurumlar,

23 İsmail H. Demircioğlu ve Muhammed A. Tokdemir, "Değerlerin oluşturulma sürecinde tarih eğitimi: Amaç, işlev ve içerik", Değerler Eğitimi Dergisi, 6/15, 69-88 (Haziran 2008) 73 .

${ }^{24}$ Sezai Öztaş, "A Literary Genre in Value Education in History Courses: Poems", Journal of Education and Training Studies, 6/5 (May 2018), 34.

${ }_{25}$ Uwe Krause, "Avrupa Değerler Atlası: Avrupa Perspektifinden Değerler Tartışması", Değerler Eğitimi Eğitimde Farklılık ve Katılım Hakkı, der. A. Kaya, G. Vural, A. Aydın, trc. İlkay Südaş (İstanbul: İstanbul Bilgi Üniversitesi Yayınları, 2016), 4.

${ }^{26}$ Güngör, Değerler psikolojisi, 29.

27 Amudson, Teaching values and ethics, 20. 
öyle bir fiili durum meydana getirdi ki, orada ferdî davranışların en görünür yönü, bu davranışları şemalar halinde biçimlenmesidir. Şartlandırılmış reflekslerin reklam kurgusundan tutun da, duygusal klişelere, önceden hazırlanmış formüllere göre kitlelerin siyasî tepkilerini belirginleştirmeye varıncaya kadar, insanın tarihî atılım ve harekete geçme anı ikinci plana itiliyor. Evet sorumlu varlık olarak hareket eden ve verdiği kararla, fiilen yeni bir geleceğin açılışına katkıda bulanacak olan o insan rolünden uzaklaştırlıyor. Çünkü hadiseler sadece yüzeysel göründüğünde, bütün tarih, sırf kendi etkinliğine sahip yapıların bir diyalektiğine indirgenebilir gibi gelir. Öyle ki, yapıdan hareketle onu doğuran insanî eyleme yükselme, insanî eylemi arayıp bulma ihtiyacı bile hissedilmemeye başlar. Bu bakış açısı içinde, insan "yapılar tarafindan sahneye konulmuş bir kukla gibi düşünülür" ve sonunda Michel Foucault ile birlikte “insanın ölümü" ilan edilir."28

Aslında bu tartışma, aynı zamanda ahlâk ile ilgili bir tartışmayı da beraberinde getirmektedir. Zira ortaya koyduğumuz davranışların iyi veya kötü olduğuna dinin bizzat kendisi karar verdiği gibi, normatif bir ilim olan ahlâkın da davranışlarımız ile ilgili ortaya koyduğu değerler vardır. Dinin, hüküm bildirmediği alanlarda çoğu zaman ahlâkî esaslar, bazen de örf yani sosyal normlar belirleyici bir rol alır. Sosyal normların devreye girdiği yerde, zaten yine ahlâktan söz ediyoruz demektir.

Çoğunlukla insanın ahlâkî davranışında rol oynayan unsur ahlâkla ilgili bilgiler değil, duygulardır. İnsan pişmanlık veya vicdan azabı duymadığı takdirde yanlış ve kötü olarak bildiği hareketleri çok rahatlıkla yapabilir. ${ }^{29}$ Yanlış hareket ve tutumları engelleyen, vicdan dediğimiz olgudur. Vicdan dediğimiz şey aslında bir kaideler bütünüdür. $\mathrm{Bu}$ sistem insanın kendi davranışları veya başkalarının davranışları hakkında "doğru” veya "yanlış" yargılar yapmasına yarar. ${ }^{30}$ İnsanın davranışları yönlendirmeye başlayan duygular, muhakkak ki bir referans değere göre kendisini şekillendirir. Bu referans değerler veya diğer bir ifade ile standart değerler, ya dinler tarafından belirlenip empoze edilir veya toplumun ahlâkî kurallarından çıkarılır. Dinin ortaya koyduğu esaslar, çoğu zaman İlahî bildirimle anlaşılır; toplumun ortaya koyduğu kuralların bir kısmı ise, akıl sayesinde doğruluğu veya yanlışlığı test edilir.

Günümüzde dinî değerlerden mahrum mevcut sistemlerin getirdiği boşluklar, yeni değerler eğitimi ile doldurulmaya çalışıldı. 1990'lardan itibaren arzu edilen

${ }^{28}$ Roger Garaudy, İslam ve İnsanlığın Geleceği, trc. Cemal Aydın, (İstanbul: Pınar Yayınları, 2015), 125 .

${ }^{29}$ Erol Güngör, Ahlâk psikolojisi ve sosyal ahlâk, (İstanbul: Ötüken Yayınları, 1997), 57.

${ }^{30}$ Güngör, Ahlâk psikolojisi, 56, 57.

Turkish Academic Research Review - Türk Akademik Araştırmalar Dergisi https://dergipark.org.tr/tr/pub/tarr 
ilgiyi bulan değerler eğitimi, ${ }^{31}$ toplumda ve özellikle gençler arasındaki ahlâkî çöküntü ve sosyal huzursuzlukların giderilmesi için nihayet başvurulan bir çare olmuştur.

Sosyal öğrenme teorileri, insanın nasıl sosyalleştĭgini, yani toplumun hangi tip etkileriyle ahlâk normlarının ve değerlerinin öğrenildiğini araştırırlar. Sosyal teoriyi benimseyenlere göre, ahlâkî davranışın edinilmesi ile norm ve değerlerin öğrenilmesi aynı psikolojik proseslere dayanan benzer olaylardır. ${ }^{32}$ Değerlerin öğrenilmesi, bir başka ifadeyle ahlâk esaslarını doğuştan beraberimizde getirmeyip sonradan öğrendiğimize göre, sosyalleşme de sonradan öğrenilmekte ve aynı zamanda doğrudan eğitimle ilişkilidir. Doğrusunu söylemek gerekirse sosyalleşme bir öğrenme biçimidir. Kendimiz için iyi ve doğru olan ile diğer insanlar için iyi ve doğru olanı birleştirdiğimiz zaman, kişi ve toplum değerlerinin çatışmasız bir alanını oluştururuz. Bu meyanda bütün toplumlarda yaşayan ve her daim canlı olan değerleri Sorokin "kalıcı değerler"33 olarak nitelendirir.

İçinde yaşadığımız çağda hem ferdî hem de sosyal değerlerin önemi az çok kavranmış görülmektedir. Değerler eğitimi programları da bu ihtiyaca göre şekillenmektedir. Bunun devam ettirilmemesi durumunda, değerler etkisini kaybedecek ve bu da beraberinde toplumların çöküşünü tetikleyecektir. Schweitzer'in, gelişen her uygarlığın büyük bir canlılıkla işleyen asgari bir ahlâk değerleri bütünü olduğu ve ahlâk değerlerindeki çöküşte, uygarlığın çöküşünün ayrılmaz bir parçası olduğu yolundaki iddiaları doğru görünmektedir. ${ }^{34}$ Bundan sonraki çabamız, değerler eğitimi ile birlikte sosyal hayatın kalitesini yükseltmek olmalıdır.

Günümüzde birçok ülkede ve özellikle de ülkemizde toplumu yeniden şekillendirmek ve bireylerin karakterini oluşturmak için ortaya konulan değerler, genellikle Batı medeniyetinin taşıyıcılığını yaptı̆̆ı değerlerdir. Bu sebeple öncelikle Batı değerlerinin esaslarını öğrenmek durumundayız.

\section{Batı Değerlerinin Temel Özellikleri}

Her medeniyeti besleyen altyapı unsurları vardır. Batı medeniyetini oluşturan da şüphesiz Yunan felsefesi, Hıristiyan inancı ve Roma hukukudur. Bu üç anlayışın meydana getirdiği kültür hamulesi, Batı dünyasının zihin hançeresini

\footnotetext{
31 Howard Kirschenbaum, Enhance values and morality in schools and youth settings (Massachusetts: Allyn\&Bacon Company, 1995), 4.

32 Güngör, Değerler psikolojisi, 40.

${ }^{33}$ Sorokin, Bir bunalım çağında toplum felsefeleri, 174.

34 Sorokin, Bir bunalım çağında toplum felsefeleri, 319.
} 
şekillendirmiştir. Şüphe yok ki her kültürün kendine has ve kendi toplumundan neşet eden değerleri vardır. Elbette bütün Batı değerlerini yeknesak ve bir bütün görmek, haklı olarak tenkitlere sebep olabilir. Zira değerler, herşeyden önce bir bilgi problemidir. ${ }^{35}$ Bilgiyi değişik formlarda ele alan anlayışların kaçınılmaz olarak değerlerle ilgili yorumları ve bakışları da farklı olacaktır. Ancak çeşitli değer yaklaşımlarına sahip olsa bile Batı dünyasının dışa vurumunda belirgin bazı değerlerin öne çıktığı görülmektedir. Günümüzde bu öne çıkan Batı değerlerinin de kendine özgü bazı özellikleri vardır. Bunların bir kaçına aşağıda değinmeye çalışacağız.

\subsection{Batı Değerleri Ferdidir}

Romalı düşünür ve seyyah Tacitus'un işaret ettiği gibi Batı insanı tekil yaşayan insanlardır, antlaşma ve sözleşme etrafında toplanırlar. Bir kontrat (akit) toplumudur ki bu da barbarlığın temelinde olan bir şeydir. ${ }^{36}$ Jean-Jacques Rousseau'nun Social contract (Sosyal contrat) ${ }^{37}$ ile işaret ettiği aslında budur. İlber Ortaylı, Batı ile Doğu toplumu arasındaki en belirgin farkl1lığın bundan doğduğuna işaret etmek üzere şunları söyler: "Doğu toplumunda nizamî ilişkiler, kan bağı, sülalevî ilişkiler çok hâkimdir. Çünkü tarihî gelişimi itibariyle medenî toplumdur. Yani şehir toplumudur. İşte bu en büyük ayrımdır."’38

Fert ve hakları konusunda ilk kalem oynatanlardan biri olan John Locke, kendisini ünlü yapan Hükümet üzerine ikinci inceleme ${ }^{39}$ adlı eserle bunun temelleini atıyordu. Batı ahlâk ve değer anlayışını belirlemede bir dönüm noktasını teşkil eden Aydınlanmacı Immanuel Kant, ahlâkı ve buna bağlı olarak değerleri toplum şartlarından ve ihtiyaçlarından kopararak liberal bireyci toplum için kabul edilebilir bir moral forma dönüştürür. ${ }^{40}$ Georg Simmel ise bireyselciliği "kilisenin paslı zincirlerinden ilkesel olarak kurtulma"41 diye nitelendiriyordu. Dolayısıyla Batı'da bireyselciliğin laik anlayışla çok sıkı bir ilişkisi olduğuna sadece işaret etmekle yetinelim.

35 İoanna Kuçuradi, İnsan ve değerleri, (İstanbul: Yank1 Yayınları, 1971), 26.

36 İlber Ortaylı, Avrupa ve Biz (İstanbul: İş Bankası Yayınları, 2007), 261.

37 Jean Jacques Rousseau, The social contract and discourses (Indiana: Liberty Fund, Inc., 2010).

${ }^{38}$ Ortayl1, Avrupa ve Biz, 261.

39 John Locke, Two treatises of gowernment (Dublin: Thomas Tegg, 1823).

${ }^{40}$ Maclntyre, Etik'in kisa tarihi, 224.

${ }^{41}$ Simmel, Bireysellik ve kültür, 215.

Turkish Academic Research Review - Türk Akademik Araştırmalar Dergisi https://dergipark.org.tr/tr/pub/tarr 
Alexis de Tocqueville de, "bireycilik" kavramını 1830 yılında, Amerika'da gözlemlediği, servet ve görgü sahibi, kitlelerden yalıtılmış bireyler için kullansa da, ${ }^{42}$ neticede önemsenen bireyi öne çıkarma peşindeydi. Ahlâkî esasların ve buna paralel olarak değerlerin, ferdiyetçiliğin öne çıkmasıyla birlikte toplumdan soyutlanarak ele alındığı ve kişiselleştirildiğini görmekteyiz. Artık bireyselcilik, modern toplumun ahlâkî şifresidir. ${ }^{43} \mathrm{Bu}$ bakımdan toplumun değerlerin ortaya çıkmasındaki önemini küçümsemek adına Martin Luther için topluluk, "öncesiz-sonrasız bir selamet dramasının sadece dekorudur." ${ }^{4} \mathrm{Ne}$ var ki Luther, ferdi ahlâkçılığı Tanrı'nın kurallarıyla belirliyordu ve bunların aklî bir temeli aranamazdı.

Bir dönem Hıristiyanlığın tamamen Aristoteles'in yorumlarına teslim edilmesine ve bu anlayıştan beslenerek değer ve ahlâkî kuralların oluşmasına kızan Martin Luther, Aristoteles'ten "Kilise'yi yoldan çıkarmış o soytarı" olarak söz ediyordu. Luther, öğretisinin çoğunda ortaçağ Katholik öncüllere sahip olduğu halde, dünyevi otoritenin mutlak haklarını desteklemesi bakımından emsalsizdi ve emsalsiz olmakla övünüyordu. Luther'in moral teorinin tarihi için taşıdığı önem burada yatar. Seküler dünyanın kendine özgü aygıtlara bu teslim edilişi, Luther'in günah ve aklanma öğretisi tarafından daha da kolaylaştırılır. ${ }^{45}$ Böylece Luther, öncülük ettiği Hıristiyan mezhebininin ahlâkî esasları ve değerlerini seküler anlayışa bir yardımcı aygıt olarak devreye sokmaktadır. Bireyin bu şekilde toplumun değerlerinden koparılmasını Richard Sennett, Kamusal insanın çöküşü ${ }^{46}$ olarak nitelendirmektedir.

Batıda olgunlaşan ferdiyetçi değerler, Jean-Jacques Rousseau'nun ortak iyiye ulaştıran vicdanî değerleri sayesinde toplumun normlarıyla buluşur ve genel iradenin sesi olmaya çalışır. "Genel irade daima haklıdır ve kamusal avantajı teşvik eder; fakat bundan halkın müzakerelerinin daima aynı ölçüde haklı olduğu sonucu çıkmaz. Bizim irademiz daima kendi iyimize yönelir, ama o iyinin ne olduğunu her zaman görmez; halk hiçbir zaman yozlaşıp çürümez, ama çoğu kez aldatılır ve ancak böyle vesilelerle kötü olan şeyi irade eder görünür."47 Rousseau'nun bu anlayışına Friedrich Hegel de omuz verecektir. Kendisinden sonra felsefenin olmayacağ1 zehabına kapılan Hegel, ahlâkî normlar ve değerlerin de son noktasını koyduğunu düşünür. Ahlâki hayatın yalnızca belli bir topluluk tipi içerisinde yaşatılabileceği ve

${ }^{42}$ Anthony Elliott \& Charles Lemert, Yeni Bireycilik Küreselleşmenin Duygusal Bedelleri, trc. Başak Kıcır (İstanbul: Sel Yayıncılık, 2011), 10.

${ }^{43}$ Elliott, Yeni Bireycilik, 24.

${ }^{44}$ Maclntyre, Etik' in Kısa Tarihi, 137.

${ }^{45}$ Maclntyre, Ethik'in Kisa Tarihi, 138.

${ }^{46}$ Richard Sennett, Kamusal insanın çöküşü, trc. Serpil Durak, Abdullah Yılmaz (İstanbul: Ayrıntı Yayınları, 2013).

${ }^{47}$ Rousseau, The social contract, 20. 
böyle bir topluluk içerisinde belli değerlerin vazgeçilmez görüleceği kanaatindedir. ${ }^{48}$ Oysa ki halis bir moralitede, otoriteye sahip olanlar kurallardır, bireyler değildir. ${ }^{49}$ $\mathrm{Bu}$ düşünceler, kişisel değerleri toplumun değerleriyle bir arada ele alınmasını sağladı. Böylece her ne kadar fert vurgusu ağır bassa da değerlerde, toplumun yararı da gözönüne alınmaya çalışılmıştır. Zira bu anlayışa göre bireyler, toplumsal roller içerisinde bizzat kendilerinin bilincine varırlar. Bu durumu Zygmunt Bauman, "Bireyselleşmiş Toplum" olarak ifade etmektedir. ${ }^{50}$ Dönemin İngiltere Başbakanı Margaret Thatcher ise, buna şiddetle itiraz ediyordu: "Toplum diye bir şey yok, sadece bireyler ve aileler var." ${ }^{51}$ Kabul etmeliyiz ki günümüzde zaman zaman toplum vurgusu yapılsa da, artık Batı'da bireyselcilik ve buna bağlı değerler revaçtadır.

Kişisel değerlerin önemi ve önceliği, fertten ferde değişebilir; bir zengin için cömertlik, bir çoban için koruyuculuk, bir asker için cesaret, bir eş için sadakat değerler hiyerarşisinde en yüksek değer olarak kabul edilir. Toplumsal değerlerin de adaletle ciddi bir ilişkisi olduğunu gözardı edemeyiz, çünkü adalet kişiye değer bahşeden bir olgudur ve erdemliliği tevşik etmektedir. Aynı zamanda adalet, toplumun her ferdi tarafindan istenen ve arzu edilen bir değerdir. Bütün bunlarla birlikte, ayrıca değerlerin nerede zuhur ettiği de önem kazanmaktadır; yarışta koşmak ile savaştan kaçmanın zıt değerler taşıdığı ortadadır. Ancak burada esas ve tehlikeli olan şey, birey ve değerlerinin öne çıkarılmasının, ahlâkî değerleri kontrol eden ve yöneten sosyal kural ve ilkelerin riske atılması veya boşa çıkarılmasıdır. Toplumca kontrol edilen ve özümsenen ahlâkî değerlerin, çoğu kez sosyal bunalımlardan çıkmanın veya daha kolay atlatmanın bir vasıtası oldukları unutulmamalıdır.

\section{2- Batı Değerleri Pozitivizmden Etkilenmiştir}

Özellikle başlangıçta realist anlayış ve akabinde buna bağlı gelişen pozitivist felsefeye bağlı olarak bilimin merkeze alınması, değerler anlam dünyasını da kökten sarsmış durumdadır. Çünkü buna göre bir şeyin bilimin alanına girebilmesi için değerlerden soyutlanmış, objektif bir yaklaşıma konu olması gerekir. Oysa değerler objektif değil subjektif bir yargının neticesidir. Bu da tabii olarak geçmişte kabul gören değerlerin bir kenara atılması sonucunu doğurmaktadır.

\footnotetext{
${ }^{48}$ Maclntyre, Ethik'in kisa tarihi, 237.

${ }^{49}$ Maclntyre, Etik' in kisa tarihi, XI.

50 Zygmunt Bauman, Bireyselleşmiş toplum, trc. Yavuz Alogan (İstanbul: Ayrıntı Yayınları, 2005).

${ }^{51}$ Elliot, Yeni Bireycilik, 29.
}

Turkish Academic Research Review - Türk Akademik Araştırmalar Dergisi 
Muhakkak ki ahlâkî davranışla ilgili inançlarımız birer “değer hükmü” (yargısından) ibarettir. Bir kimsenin iyi dediği davranış bir başkasınca öyle değerlendirilmiyor, bir kimsenin ulaşmak için çaba harcadığı hedef bir başkasınca kıymet ifade etmiyor olabilir. Böyle olunca, geçen yüzyıldan beri hayli pozitivist bir ton kazanmış olan ilim geleneğinin, ahlâk problemini yeniden değerlendirmesi ve yapılandırması kaçınılmazdı. Halbuki değer hükümlerinin operasyonel tarifleri yapılamadığına göre onların ilmi de olamazdı. Zaten gün geçtikçe gelişen sosyoloji ve sosyal antropoloji araştırmaları değer hükümleri konusunda tam bir kültürel rölativizmin hakim olduğuna işaret etmektedir. Böylece, sosyal ilimlerde ahlâk problemi insan gruplarının ne kadar değişik şeylere inandığını göstermeye yarayan bir etnolojik malumat yı̆̆ını haline gelmiştir. ${ }^{52}$

Realistler ve onlardan sonra sahneye çıkan Pozitivistler, supjektif bir olgu olarak kabul ettikleri ahlâkı, ilmi saymanın mümkün olmadığı kanaatine varmışlardı. Bu dönemlerde "değerler" de tek başına bir olgu olarak ortada olmadığından ahlâkî esasların içinde ele alınmaktaydı ve genel bir ifade ile ahlâkî değerler veya ahlâkî hükümler olarak karşımıza çıkmaktaydı. Ancak uzlaşmacı pozitivistlerin başı olan Agusut Comte, ortaya koymaya çalıştığı “insanlık dini”nde bazı ahlâkî esaslar vaaz etmek zorunda kalınca, ahlâkı, ilimler sınıfından saymak zorunda kalmıştı. Özellikle Comte'un bu anlayışından Morley, Durkheim, Spencer gibi filozofların etkilendiğini ${ }^{53}$ belirtmek durumundayız. Böylece bir zaman ahlâkî esasları ciddiye almayan pozitivistler, yeni değerler ortaya koymak açısından bu alan ile ilgilenmeye başladılar.

Bugün kalıcı ve çoğu kez apaçık kabul ettiğimiz değerlerin önemli bir kısmı, Rönesans ve Bilimsel Devrimden sonra ortaya çıkmıştır. Yeniden şekillenen sanat ve bilim, Orta Çağ'ın değerlerini temelden değiştirdi ve bu değişim bizi daha derinden modern insan yapan şeylere doğru ilerleyen bir "zenginleştirme” (!) oldu. Batı dünyasında materyalist ve poztivist anlayışın el ele vererek, Hıristiyanlık inancı ve idealizme karşı yüzyıllara dayanan savaş ve çatışmadan dolayı aşındırdı. Dinî ve ahlâkî normlar ile insanî kıymet hükümlerinin sosyal hayattan çekilmesiyle meydana gelen boşluk, "değerler" kavramıyla doldurmaya çalışılmakta ve bunların eğitim yoluyla benimsetilmesi istenmektedir.

Bilimin ilk ihtiyaçları, bağımsızlık ve özgünlük, muhalefet ve özgürlük ile hoşgörüdür. Bunlar bilimin kendi başına talep ettiği ve şekillendirdiği değerlerdir. Bilim adamları toplumu, bir demokratik toplum olmalıdır. Bunlara göre, etik

52 Güngör, Değerler psikolojisi, 13.

53 Güngör, Değerler psikolojisi, 20. 
sorunun özü, özel ve kamusal ihtiyaçları birleştirmektir. Bilim insanları, "adalet, şeref, insanın insana saygısı. Bu insanî değerlerin bilimle ne alakası var?” diye soruyorlar. Geçmişte eleştirmenler, bir bilimin nasıl geliştiğini görmek için pratik olarak bakmış olsalardı, böyle bir soru sormazlardı. Zira bilim, bir insanın işi ile diğerininkiyle yüzleşir ve her birine bilimsel metodu aşılar ve uygular.

Bir insan ile diğer bir insan arasında adalet, onur ve saygı olmadan yaşanılamaz. Bilim, gerçeği keşfetmek için ancak bu yollarla kararlı amacının peşinden gidebilir. $\mathrm{Bu}$ değerler olmasaydı, bilim insanları topluluğunun bilimin pratiğini mümkün kılmak için bunları icat etmesi gerekecekti. Nitekim bu değerlerin olmadığı toplumlarda, bilim onları icat etmek zorunda kaldı. Bilim bir mekanizma değil, insani bir ilerlemedir. Ancak insan araştırması, hiçbiri nihai olmayan adımlarla öğrenmedir ve bir neslin hataları, bir sonraki tarafından düzeltilmeleri kaydıyla, adeta bir merdivenin basamaklarıdır. Bilimin değerlerinin, tanınabilir biçimde insanî değerler olarak ortaya çıkmasının nedeni budur. Çünkü bilim adamları, yanılabilir olmalı ve yine de bir toplum olarak hatalarını düzeltmek için örgütlenmelidir. ${ }^{54}$

Maclntyre, After Virtue'de pozitivist eğilimdeki moral filozofların, moral yargıları tutum ve duygu ifadeleri olarak almakta, moral meselelerin çözülemezliğine ve moral ihtilafların bitmez tükenmezliğine en büyük katkıyı yaptıklarını ve halihazırdaki "moral durumumuz"un bu filozoflardan ödünç alınan bir nitelemeyle "emotivist" olduğunu belirttir. $\mathrm{O}$, bu durumun kaynağını “Aydınlanma projesinin başarısızlı̆ı̆”nda bulur. Maclntyre'a göre Aydınlanma düşünürleri, moralitenin geleneksel ve batıl formları diye düşündükleri şeyin yerine, bir tür dünyevî moraliteyi geçirme girişiminde bulunmuşlardır. ${ }^{55}$ Gerçekten de günümüzde tahrif edilmiş ve etkisiz kalmış değerlerin bıraktığı boşluktaki sıkıntılar, Aydınlanma projesinin başarısız sonuçlarından biridir.

\subsection{Batı Değerleri Din Dışı ve Sekülerdir}

Artık yıkılan ve "doğma" diye nitelenen eski değerlerin yerine yeni bir "kutsal" ikame edilebilirdi: Bilim. Bilimin yardımıyla yeniden şekillenen zihin kalıpları, kurgusal (spekülatif) zihne karşı, duyulara; görünmeyene karşıllı (metafizik) görünen dünyaya inanmanın çağrısıydı. Böylesi kabulleri temel alan ve prestiji giderek artan bilimsel dünya görüşü, geçmişte tali bir sonuç olarak insan nevinin manevi, estetik ve sevgiye dayalı yaşantılarını kapı dışarı etmeye ve bu nedenle de

${ }^{54}$ Bronowski, Science and human values, 80-82.

${ }^{55}$ Maclntyre, Ethik'in kisa tarihi, XV.

Turkish Academic Research Review - Türk Akademik Araştırmalar Dergisi https://dergipark.org.tr/tr/pub/tarr 
sübjektif yaşantılara dayanan değer sistemlerini de itibardan düşürmeye muvaffak oldu. ${ }^{56}$

Bundan böyle insanlar semavi mesajlar ile değil, dünyadan devşirdikleri bilgilerle hayatlarına yön vereceklerdi. "Sekülarizasyon” olarak da ifade edilen bu anlayış, hayatın sadece siyasi ve sosyal alanlarını değil, aynı zamanda kültürel yönlerini de kuşatmaya çalıştı. Zira bu anlayış, "sembollerin ve kültürel bütünlüğün din tarafindan belirlenmesinin sona ermesi”ni; kültür ve toplumun "dinî denetimin ve kapalı metafiziksel dünya görüşlerinin vesayetinden kurtulmasını" geri dönüşü olmayan bir tarihi süreç olarak kabul etmektedir. Özgürleştirici bir gelişme olarak kabul edilen sekülarizasyonun üç meyvesi olmuştur: "Tabiatın tılsımının bozulması", “siyasetin kutsallıktan soyulması" ve “değerlerin kutsallıktan arındırılması." 57 Yani sekülerleşme ile birlikte dinî bilgi ve görüşler ve bunların ortaya koyduğu değerler, bir daha geri dönmemek üzere kapı dışarı edilmeye çalışılmıştır.

Modernleşme ve dünyevileşme/sekülerleşme sürecinin üç temel değişimin açılımı şöyledir: Birincisi, "toplumsal farklılaşma" olarak ifade edilir. Yani dinin çok işlevli olduğu geleneksel toplumdaki durumun modernleşme ile birlikte değişime uğrayarak, dinî kurumların yerini farklı kurumların almasıdır. İkincisi, “toplumsallaşma”dır. Bu da, küçük ölçekli toplulukların yani cemaatlerin yerini, büyük ölçekli ticari ve sınaî girişimler ile ulusal düzeydeki gayri şahsi bürokrasinin alması sürecidir. Yani cemaat yerine "toplum” birey hayatının odağı haline geldikçe, kaynağını ve gücünü cemaatlerden alan din de zayıflayacaktır, hatta giderek hayatın dışına sürüklenecektir. Üçüncüsü ise, "rasyonelleşme”dir. Bu, insanların düşünme ve eylemde bulunma tarzıyla ilgili olup dünyevî amaçlar için teknik olarak etkin araçların izlenmesini öngörür. Teknik rasyonalitenin gelişmesi, doğaüstü güçlere olan inancı, dolayısıyla dinleri ve aynı temele dayanan ahlâkî mülahazaları tedricen kamu hayatından uzaklaştıracaktır. Bunların yerine "objektif performans" veya "pratik uygunluk" mülahazaları geçmiş olacaktır. ${ }^{58}$

$\mathrm{Bu}$ süreçler neticesinde insanlığın, kendisini dinî ve yarı dinî anlayışlardan azade kılarak dünyanın ellerinde olduğunu ve bundan böyle eylemlerinden dolayı talihini ya da ceza tanrıçalarını suçlayamayacağını keşfederek, bakışlarını öteki

56 Willis Harman, Küresel zihniyet değişimi, düşünme tarzında yeni çağ devrimi, trc. Muhammed Şeviker (İstanbul: İz Yayınları, 2000), 40; 47.

${ }^{57}$ Nakib el-Attas, "İslâmi dünya görüşü: Genel bir çerçeve", İslâm ve Modernizim, (İstanbul: İstanbul Büyükşehir Belediyesi Kültür İşleri Daire Bşkanlığı Yayınları, 1997), 31.

${ }^{58}$ Mustafa Erdoğan, “Sekülerizm, laiklik ve din”, İslâmi Araştırmalar Dergisi, 8/3-4 (1995), 179,180 . 
dünyalardan bu dünyaya ve bu zamana çevireceği düşünülmekteydi. ${ }^{59}$ Geleneksel dinlerin modern insanın ihtiyaçlarını karşıllayamayacağı da, bu düşünceleri süsleyen başka bir fanteziydi. Dinde cevabı aranan veya tatmini istenen ihtiyaçlar o kadar evrenseldir ki, bu ihtiyaçları değil, belki onları tatmin şekli değiştirilebilirdi. ${ }^{60}$ Nitekim Auguste Comte, çok daha radikal bir girişimde bulunmuş ve bu dinlerin yerine rasyonalist bir din kurmak istemiş, daha da ileri giderek "Pozitivizmin İlmihali”ni bile yazmıştı. ${ }^{61}$ Bryab Appleyard, bilimin merkezileşmesinden şöyle yakınıyordu: "Bilim hepimizi kendi şahsi ve hususi sebeplerimize hapsetti. Bizi dünyamızdan koparırken, bilinçlerimizin yüksek, zırhlı kulelerini kilitledi. Hariçte ya aldatıcı ya da manasız bir yabancı manzara, içte de varlığından emin olduğumuz yegâne mülk vardı: kendimizi bilmeye dair hiç durmayan ve endişeli bir iç gevezelik. Ruhlarımız, bedenlerimizden uzaklaştırıldı." ${ }^{\prime 62}$

İnsanlık artık "bilimsel" zamanın hayal dünyasında "modernliğin" düşlerini kurabilirdi. İnsanlığın bu rüyası da öncekiler gibi kısa sürelidir; beklendiği gibi modernitenin eskimesi de uzun sürmemiştir. Modernizm, sekülarizm ve liberalizmden ilham alan hümanist anlayışların, "bireysel özgürlük" adına yaptıkları tahribat ve tüketilen değerlerin neticesinde toplumda kürtaj, pornografi, eşcinsellik ve ailenin yıkılması şeklinde ahlâkî bir dejenerasyona yol açtığına dair yapılan suçlamalar ile karşı karşıya kalmakta gecikmedi. ${ }^{63}$ Sosyal alanda açılan yaralar gitgide insanı dehşete düşürecek boyutlara ulaşıyordu. Aslında bu insanı zehirleyen kötü sonuçlar sebebiyle günümüzde değerlere yapılan vugunun ve ihtiyacın düzeyi bir hayli yüksektir. Neticede toplumu yeniden bütünleştirmek, sağlıklı bir bünyeye kavuşturmak, fertlerin serkeşliğinden doğan ahlâkî çöküntüyü durdurmak için yeni bir değerler bütününe olan ihtiyaç ciddi şekilde hissedilmeye başlandı.

Bugün Amerika'da değerler eğitiminde ilk şart, teşvik edilen değerlerin açıkça seküler olması ve doğası gereği dinî olmamasıdır. ${ }^{64}$ Şimdi durum öyle bir noktaya geldi ki, din ile ilgili konuşmak laik ve seküler zihniyetlilerin uykusunu kaçırmaktadır. "Tanrı, Kendisi’nden başka herhangi bir şey hakkında konuşamaz." Léon Bloy'un İncil hakkındaki bu notu, önemli bir yarı-hakikattir. ${ }^{65}$ Oysa

59 Attas, İslâmi dünya görüsü, 31 .

${ }^{60}$ Erol Güngör, Türk kültürü ve milliyetçilik, (İstanbul: Ötüken Yayınları, 1989), 171.

${ }^{61}$ Auguste Comte, Pozitivizm ilmihali, trc. Peyami Erman, (İstanbul: M.E.B. Yayınlar1, 1952).

62 William Chittick, "Anlam arayışı”, Sûfí psikolojisi, ed. Kemal Sayar, (İstanbul: Kapı Yayınları, 2016), 292, 293

${ }^{63}$ Erdoğan, Sekülerizm, laiklik ve din, 181.

${ }^{64}$ Kristen J. Amundson, Teaching values and ethics an AASA critical issues report problems and solutions, (Arlington: American Association of School Administrators Library and Congress, 1991), 20.

${ }^{65}$ Maclntyre, Ethik'in kısa tarihi, 125.

Turkish Academic Research Review - Türk Akademik Araştırmalar Dergisi 
Amerika'nın devlet olarak ortaya çıktığı dönemlerde, okullarda biraz okuma ve basit matematik konuları dışında neredeyse tamamen değerler eğitimi veriliyordu. ${ }^{66}$ Tabii ki bu dönemde öğretilen değerler, Kilise'nin değerleriydi. Winconsin Journal of Education'da 1880'lerde yazılmış bir makalede şunlar kaydediliyordu: "Dinî ahlâka aykırı olmayan ama insan deneyimlerinin sonucu olan, tüm medeni insanlar tarafından tanınan, tüm ulusların filozofları tarafından öğretilen ve tüm ihtişamlı inançlar tarafından onaylanan seküler bir ahlâk vardır.” Böylece bir dönem sonra dinî değerler yerlerini seküler değerlere terk etmiş oluyordu. Gerçekte, yine de, devlet okullarının ahlâkî eğitimi, güçlü bir şekilde belirli bir Protestan Hıristiyanlığına dayanıyordu. Önemli sayıda Roma Katoliği de dahil olmak üzere birçok ebeveyn, bu tür doğrudan ahlâkî öğretime karşı çıktı. Bazıları kendi dinî okullarını kurmaları gerektiğini şiddetle hissettiler. Cincinnati'de, İncil'in hangi versiyonunun devlet okullarında okunacağı konusundaki çatışma, Tüfek Savaşı olarak bilinen şiddetli bir kavgaya dönüştü. ${ }^{67}$

Daha yakın zamanlarda Spengler; peygambervâri bir eda ile Batı'nın Çöküşü'nü haber verirken bunun nedeni olarak Batı kültürünün "uygarlıklaşma" sürecine girmesini göstermektedir. Ona göre bu uygarlıklaşma süreci, ahlâkî alanda bazı olumsuz gelişmelerle birarada ortaya çıkmaktadır. Bu gelişmeler de her yüksek kültürün, kültür devresindeki bazı değer ve kurumlarının bir yozlaşması olarak kendisini göstermektedir. Mesela kültür devresindeki "yuva”, "1rk", "kan grubu” yerine, uygarlık devresinde "kozmopolitik"; "yürek dili" yerine "bilimsel dinsizlik"; saygı, gelenek, yaşlılara karşı hürmetkâr olmak yerine "soğuk olgusallık"; "halk" yerine "kitle", "devlet-millet" yerine "milletlerarası toplum"; gerçek, canlı değerler yerine, para ve soyut değerler geçmektedir. ${ }^{68}$

Spengler, aslında bazı emarelerin önceden haber verdiği olumsuzlukların kehanetini dillendirmişti. $\mathrm{Bu}$ kehanetin zuhuru, değerler sahasındaki yıkımın neticesidir. Bunu asıl sebebi, bütün değerleri dünya için oluşturmak ve dinî değerleri hayat sahasından uzaklaştırmaktır.

\section{4- Batı değerleri Demokrasiyi Güçlendirmek İçindir}

Genel olarak ahlâkın siyasetle ve dolayısıyla değerlerin de politika ile çok sıkı ilişkisi olduğu bilinmektedir. Bu sıkı ilişkiye işaret eden filozofların başında Platon

${ }^{66}$ Amudson, Teaching values and ethics, 17.

${ }^{67}$ Amudson, Teaching values and ethics, p. 18.

68 Oswald Spengler, The decline of the west, trs. Charlies Francis Aykinson (New York: Alfred A. Knope, 1926). Konu ile ilgili değerlendirmeler için bkz. Sorokin, Bir bunalım çağında toplum felsefeleri, 105; Ahmed Arslan, İbni Haldun, (İstanbul: İstanbul Bilgi Üniversitesi Yayınları, ts.), 133, 134. 
ve Farabî gelmektedir. Bu münasebetle bir kısım felsefeciler, ahlâk felsefesini siyaset felsefesinin bir alt dalı dahi saymışlardır. ${ }^{69}$ Bundan dolayı bazı değerlerin Batı dünyasının en ideal siyaset şekli olan demokrasiyle bağdaştırılmasını, bu bakımdan normal bir süreç olarak değerlendirmek gerekir. $O$ halde en ideal değerlerin, en deal siyasi rejim olan demokrasiyi desteklemesi, Batıdaki düşünce ve değerler açısından doğal bir sonuçtur. Daha önce Tanrı adına ortaya konulan değerler, Tanrı adına bir yönetimin aygıtı haline getirilmişken, şimdi Tanrı'nın yerine insan ikame edilmekteydi. Demokraside ise yanılgıyı azaltmak adına insan çoğunluğu esas alınmaktadır. Rousseau, biraz daha ileri bir laf edecektir: "Halkın sesi, hakkın sesidir." ${ }^{70}$ Artık egemen Tanrı değil, insanlar olması gerekmektedir. Çünkü bütün insanlar doğru bir ahlâkî yaşantıya sahip olmaları gerektiği gibi, doğru bir seçim de yapmalıydılar.

Maclntyre'ın deyimiyle "Dünyevî iktidarın Luther'i olan Machiavelli”, ${ }^{71}$ Luther'in seküler dünyanın inşası için kolay bir destekçi kıldığı değerleri, ortaya koydukları sonuçlar bakımından bu kez demokrasinin hizmetine sunmaktadır. Machiavelli'nin işi kısmen kolaylaşmıştı, zira sekülarizm zaten demokrasinin bir sacayağını oluşturuyordu. Buna bağlı olarak Batı'da, git gide değerler Hıristiyan dinî formlarından soyutlanmıştı. Bunun öncülüğünü yapanlardan ve ateist yaftası yiyen Spinoza sinagogtan kovulmuştu; Hobbes ise Angilikan rahiplerinin saldırısına uğramıştı. Ayrıca ferdiyetçiliğin de bir yönüyle seküler değerler vaaz ettiğine yukarıda değinilmişti.

Seküler değerlerle demokrasiye güç ve destek veren akım hız kesmemiştir. Seküler anlayışın demokrasiyi güçlendiren bir yan ideoloji olduğu açıktı. 1940'lardan itibaren sahne alan John Dewey, ahlâk ve karakter eğitimi yoluyla verilen değerler eğitimini, vatandaşlık ve demokrasinin hizmetine sunmaya çalışmıştır. Şüphesiz aynı temelden beslenen pozitivist anlayış da benzer bir hizmet görmüştür. Whitehead'in de izah ettiği gibi yeni “insanlık dini”nin kurucusu Auguste Comte'un positivist doktrini temelden reddedilmiş olmasına ragmen pratikte ilkeleri hükümferma olmuştur ve özellikle de demokrasiyi beslemiştir. ${ }^{72}$ Dolayısıyla pozitivist değerler, aynı zamanda demokratik değerler olarak da karşımıza çıkmaktadır.

\footnotetext{
${ }^{69}$ Ahmet Arslan, Felsefeye giriş (Ankara: Adres Yayınları, 12. bsk. 2009), 180.

${ }^{70}$ Rousseau, The social contract, 23.

${ }^{71}$ Maclntyre, Ethik'in kisa tarihi, 143.

72 Alfred North Whitehead, Düşüncelerin Serüvenleri, trc. Yusuf Kaplan (İstanbul: Külliyat Yayınlar1, 2008), 41.
} 
Günümüz değerler eğitiminin önemli bir amacı da zaten iyi vatandaş yetiştirmeye yöneliktir. Bu bağlamda vatandaşlık eğitimi, ahlâk eğitimi ve tarih öğretimi birbiriyle örtüşen üç alandır. Bazı araştırmacıların da işaret ettikleri gibi, vatandaşlık eğitimi kaçınılmaz olarak değerler ve ahlâki eğitim ile bağlantılıdır. ${ }^{73}$ Bütün bu değerler, demokrasinin yaşaması ve demokratik kurallara uyan iyi birer vatandaşın yetişmesi içindir.

\section{Batı Değerleri Her Bünyeye Uyar mı?}

Değerlerin toplumdan topluma farklı şekillerde tezahür ettiği bir gerçektir. Her toplumun değerleri, kendi kültürünün hamurunda şekillenmektedir. Kızılderili kabilelerde görülen "potlaç" adı verilen şenlik merasiminde kabile reisi, izzet ve ikramının doruk noktasında üstünlüğünü, en kıymetli eşyalarını imha etmekle ortaya koymaya çalışır. İnsanın malsız da yaşabileceğini ispat etmek için yapılan bu fedakârlığın bir benzerini karşı kabilenin de tekrar etmesi beklenir. Aksi takdirde bütün şeref ve ahlâkını kaybettiğine hükmedilir. Maddi varlığa karşı ilgisizliği bir değer olarak ortaya koyan bu adetin bir benzeri, Malezyalılarda ve hatta cahiliye dönemi Araplarda da görülmektedir. ${ }^{74} \mathrm{Bu}$ benzerliklerin görülmesi, şüphesiz her toplumda benzer değerlere aynı anlamın yüklendiği manasına gelmemektedir. Çünkü değer neticede kültürün bir parçasıdır ve toplumdan topluma kültür farklılaşıyorsa değerler de değişecektir. Bu bakımdan Batı kültürünün ve özellikle de modern Batı'nın ürettiği değerlerin olduğu gibi Müslüman toplumlara aktarılmasının, aynı derecede kabul görüleceği ve etkide bulunacağını var saymamız doğru değildir.

Ali Sami en-Neşşâr'ın haklı olarak: “Íçyapımıza ve vicdanımıza bizim dışımızdaki bir medeniyetin değerlerini yüklememiz kadar isabetsiz bir şey olamaz. Bu açık bir hatadır. Ne bizim değer yargılarımız onların değer yargılarıdır ve ne de bizim ahlâkiyatımız onların ahlâkiyatıdır. Bizim kâinatın afakındaki olaylara bakıp oradan aldıklarımızla onlarınki bir değildir. Dolayısıyla düşünce ve felsefí yolumuz aynı değildir. Bu iki felsefenin kendine özgü değişik yöntemleri ve yolları vardır"75 demektedir. Aliya İzzetbegoviç de, bir toplumun ürettiği değer ve kavramların bir başka toplulukta aynı aksülameli bulamayacağını ifade etmektedir: "Bu itibarla İslâm’1 Avrupa'nın 1stılahatıyla ifade etmek hemen hemen imkânsızdır. Namaz, zekât, halife, cemaat, abdest gibi İslâmî terimler; dua, vergi, hükümdar, toplum,

\footnotetext{
${ }^{73}$ Harbert, History of teaching, 25.

${ }^{74}$ Aliya İzzetbegoviç, Doğu Batı arasında İslam, trc. Salih Şaban (İstanbul: Yarın Yayınları, 2011), 52, 53.

${ }^{75}$ Ali Sami en-Neşşâr, İslam 'da felsefi düşüncenin doğuşu, trc. Osman Tunç (İstanbul: İnsan Yayınları, 1999), 1/10.
} 
yıkanma ile aynı manada değildir." ${ }^{\text {"76 }}$ Demek ki Müslümanların anlam yüklediği değerler, Batı dünyasındaki algıdan çok farklıdır. Aslında farklı topluluk ve kültürlerin değişik "doğru”lara sahip olduğunu Paskal, "Pirenelerin öte yanında (yani İspanya'da) doğru olan, bu yanında (yani Fransa'da) yanlıştır"'77 derken aynı şeyleri söylemek istemiştir.

Batı dünyasının düşünce alanını felsefe beslemektedir, Müslüman ülkelerde ise düşünce ve buna bağlı üretilen değerler dinî kaynaktan neşet etmektedir. Muhammed Draz, bu farklı iki yapının temel ayrılıklarını şu ifadelerle dile getirmektedir: "Felsefenin gayesi, düşünmektir; hedefi ise, katı bir düşüncedir; donuk bir halde gözler önünde canlanır. Dinin hedefi ise, hareket dolu bir güç ve atılım dolu bir ruhtur. Felsefenin ortaya koyduğu çoğu şey teoriktir; pratik bölümde bile teoriye dayanır. Dinin gayesi ise pratiktir; teorik yönü bile pratiğe dayanır." 78 Bu bakımdan, İslam dininin teorik yönü ile birlikte en ağır basan tarafı pratiğidir, yani değerler manzumesidir. Bu bakımdan Müslüman toplum ile Batılı toplumların değerlere yaklaşımı temelden farklılık gösterir. Zira Erol Güngör'ün işaret ettiği gibi: "Değer bir inanç olmak bakımından, dünyamızın belli bir kısmılla ilgili idrak, duygu ve bilgilerimizin bir terkibi demektir. Fakat değer, inancın spesifik bir şekli olmak itibariyle ondan daha yukarıda bir zihin organizasyonudur. Şöyle ki bir değer bir tek inanca değil, bir arada organize olmuş bir grup inanca tekabül eder." 79 Dolayısıyla İslam dinî, ileride de değineceğimiz gibi, birçok değerlerin organizasyonuyla oluşan bir değerler yumağını tavsiye etmektedir.

Günümüzde Batı dünyasından tek tek ele alınıp aktarılan değerlerin, bizim zihin ve gönül dünyamıza uygun düşmesi beklenmemelidir. Söz gelimi başkasına yardım veya diğergamlığı bir değer olarak ele aldığımızda dahi bu duyuş ve uygulama farklılığı çok belirgin bir şekilde ortaya çıkmaktadır. Aslında John Aubrey'in anlattığı bir hikâye Batı felsefî anlayışın bu konuya yaklaşımını bariz bir şekilde ortaya koymaktadır. Aubrey, St. Paul Katedrali'nin avlusunda, Hobbes'u yoksul bir adama sadaka verirken gören bir Anglikan papazının (herkesin gözünde dinsiz, imansiz ve ateist olan) Hobbes'a: "Acaba İsa emretmeseydi sadaka verir miydi?" diye sorarak firsattan nasıl istifade etmeye çalıştığına ilişkin bir öykü anlatır. Hobbes'un cevabı, "yalnızca yoksul adamı hoşnut ettiği için değil, fakat yoksul adamı hoşnut görmekten kendisi de hoşnut olduğu için sadakayı

\footnotetext{
76 İzzetbegoviç, Doğu Batı arasında İslam, 20.

77 Arslan, Felsefeye giriș, 30.

${ }_{78}$ Muhammed Abdullah Draz, Din ve Allah İnancı, trc. Bekir Karlığa (İstanbul: Bir Yayınları, ts.), 74,75 .

${ }^{79}$ Güngör, Değerler psikolojisi, 28.
}

Turkish Academic Research Review - Türk Akademik Araştırmalar Dergisi 
verdiği”dir. ${ }^{80}$ Dolayısıyla bu anlayışa göre, bir değer hem muhatabı hem de uygulayanı mutlu ettiği için kıymetlidir.

Oysa sadece bu örnek üzerinde konuştuğumuz vakit dahi İslam anlayışının çok daha zengin değerler örgüsüyle örüntülendiğini fark ederiz. İslam dini insanların başkasına muhtaç olmamaları için muhakkak bir çaba içinde olmalarını ısrarla vurgulamaktadır. ${ }^{81}$ Ancak kişi, bir şekilde yardıma muhtaç duruma düşmüşse mutlaka gözetilmelidir. ${ }^{82}$ Üstelik bu yardım herhalükârda karlışıksızdır. Bu bakımdan öncelikle başkasına ve özellikle yoksula yardım bir dinî ibadet olarak öne çıkmaktadır. ${ }^{83}$ Yardım yapılırken muhatabın izzeti nefsini korumak en çok dikkat edilmesi gereken bir husustur. ${ }^{84}$ Ayrıca bu yardım, başkalarına gösteriş yapmamak kaydıyla ve kişinin kendisinin de beğenmişlik yanlışına düşmemesi şartıyla istenir. ${ }^{85}$ $\mathrm{Bu}$ sebeple açıktan yardım etmektense, gizlice yapılması her iki tarafın şahsiyetini koruması için tavsiye edilmiştir. ${ }^{86}$ Yardıma muhtaç kişiye malın en güzeli verilmelidir. ${ }^{87}$ Yardım yapılırken muhatabın gönlü alınmalı ve ona güzel muamele yapılmalıdır. $^{88}$ Bütün bu değerlerle örülmüş başkasına yardım meselesi, hepsinin üzerinde Allah'ın rızasına rapt edilmiştir. ${ }^{89}$

Burada da işaret ettiğimiz gibi bir tek "başkasına yardım" olarak ele alınan değer, İslam dini söz konusu olduğunda birçok değerle içiçe olduğu gibi aynı zamanda Allah'ın rızasını kazanmaya yöneliktir. $\mathrm{Bu}$ sebeple değerlerin uygulanmasında insanî zaafların ortaya çıkmasına en başta engeller konulmuştur. Zira insanın kıymet verdiği inanç ve ahlâkî hükümler neticede belli tutumlar halinde ortaya çıkmaktadır. Tutum da, insan dünyasının belli bir kısmına ait idrak, duygu ve bilgilerimizin bir terkibi demektir. Tutumun da değer gibi başlıca üç yapıcı unsuru vardır: Bilgi, duygu, hareket. Nitekim biz bir değere sahip olduğumuz zaman onun

${ }^{80}$ Maclntyre, Ethik'in kisa tarihi, 153.

81 "İçinizden birinin bir ip alarak odun toplaması, insanlardan bir şey istemesinden (ki verirler veya vermezler) daha hayırlıdır." (Buharî, "Buyu”, 15; Müslim, "Zekat”, 36).

82 "Onlar, seve seve yiyeceği yoksula, yetime ve esire yedirirler." (İnsan, 76/8).

83 "Yahut şiddetli bir açlık gününde kendisiyle yakınlığı olan bir yetimi, yahut yerde sürünen bir yoksulu doyurmaktır." (Beled, 90/14-16).

84 "Ey iman edenler! Allah'a ve ahiret gününe inanmadığı hâlde insanlara gösteriş olsun diye malını harcayan kimse gibi, sadakalarınızı başa kakmak ve gönül kırmak suretiyle boşa çıkarmayın." (Bakara, 2/264).

85 "Mallarını Allah yolunda harcayan, sonra da harcadıklarının peşinden (bunları) bașa kakmayan ve gönül incitmeyenlerin, Rab'leri katında mükâfatları vardır" (Bakara, 2/262).

86 "Sadakaları açıktan verirseniz ne güzel! Fakat onları gizleyerek fakirlere verirseniz bu, sizin için daha hayırlıdır ve günahlarınızdan bir kısmına da keffaret olur. Allah, yaptıklarınızdan hakkıyla haberdardır." (Bakara, 2/271).

87 "Sevdiğiniz şeylerden Allah yolunda harcamadıkça iyiliğe asla erişemezsiniz. Her ne harcarsanız Allah onu bilir." (Ali İmran, 3/92).

88 "Güzel bir söz ve bağıșlama, peşinden gönül kırma gelen bir sadakadan daha hayırlıdır." (Bakara, 2/263).

89 “Rabblerine dönecekleri için verdiklerini kalpleri ürpererek verenler.” (Muminun, 23/60). 
hem tutulacak en doğru yol olduğunu düşünüyoruz, hem o konuda duygusal davranıyoruz ve değere karşı pozitif tavır takınıyor, aksi durumların aleyhinde bulunuyoruz; hem de o değer bizi belli bir istikamette hareket etmeye itmektedir. Bu sebeple psikologlar tutum ve değer kavramlarını aynı anlamda kullanmaktadırlar. ${ }^{90}$

Din, eğer bir kurallar kümesini veya bir hedefler kümesini başarılı bir şekilde ortaya koymak durumundaysa, bu tür kurallar ve hedefler 1şı̆̆ında yaşamanın insanların bağımsız bir şekilde iyi olduğuna hükmettikleri şeyi meydana getireceğini göstermek suretiyle bunu yapmak zorundadır. ${ }^{91}$ Bu münasebetle dinî kurallar ve değerler ile felsefî ve insanî değerler sureten birbirlerinden ayrılırlar. Bundan dolayı Batı dünyasının geliştirdiği değerlerin dinin şekillendirdiği değerler manzumesi ile yaşamayı adet haline getirmiş Müslüman memleketlerde olduğu gibi kabul görmesi, itibar edilmesi ve uygulanması oldukça zordur.

\section{Sonuc}

Değerlerin bilgi ile sık1 ilişkisinden dolayı değerler, daima bir düşünce ve inancın ürünüdür. Bu münasebetle değerler ya bir felsefî anlayışın ya da bir inancın eseridir. Bazı ahlâkî değerlerde, ilk etapta bir inancın veya düşüncenin izi göze çarpmasa bile içten içe toplumu şekillendiren bir kültürün dayatması nedeniyle bunlardan azade değildir. Kişi kendi kültüründen beslenen değerleri kendine mal ettiği gibi, toplumun kendisine dayattığı değerlerle de bir başka “değerler” olgusu ile karşı karşıya kalmaktadır. Ancak değerlerin kişiye dönük yönü bilgiden çok duygusal bir anlam kazanır. Çünkü çoğu zaman insanların duygu dünyaları düşüncelerinin önüne geçebilmektedir.

Onyedi ve onsekizinci yüzyıllarda bireyin öne çıkarıldığı felsefî anlayışların baskın olduğu dönemlerde nasıl ferdî değelerler önemseniyor idiyse, günümüzde de "bireyselciliğin sonu”, "öznenin ölümü” gibi beyanlarla ferdiyetçiliği ikinci plana iten ve Batı dünyasından devşirilen değerlerin, diğer bir ifadeyle "evrensel değerler" adıyla sunulan yeni değerlerin küreselleşme ile ilişkisi gözardı edilmemelidir. Zira küreselleşme en çok ekonomi ve kültür alanındadır. Kültürün değerlerle sıkı ilişkisi unutulmamalıdır. Söz konusu küresel ekonomik, siyasî ve kültürel çıkarların insanlığa sunacağı hedefler hâlâ kuşkuyla karşılanmaktadır. Bu kuşku aynı merkezden empoze edilen değerler hakkında da duyulmaktadır. Zira Batı değerler dünyasından kopuk, farklı bir ahlâkî yapıdaki toplumların bunlara entegre edilmesi

${ }^{90}$ Güngör, Değerler psikolojisi, 29, 30.

${ }_{91}$ Maclntyre, Ethik' in kisa tarihi, 130.

Turkish Academic Research Review - Türk Akademik Araştırmalar Dergisi https://dergipark.org.tr/tr/pub/tarr 
sanıldığı kadar kolay görünmemektedir. Özellikle de İslam kültürü ile yoğrulan Müslüman toplumlarda kuşkunun ötesinde bir direnç de göze çarpmaktadır.

Sosyal bünyeler, her zaman yabancı kültür ve değerlere karşı dirençli olmuşlardır. Farklı toplumlarda sosyal gerginliği gidermenin en kolay ve kestirme yolu, o toplumun bünyesiyle uyumlu değerler eğitimini vermektir. Bu başarıldığı takdirde çağımızın çoğu sancılı problemlerini daha rahat çözme imkânına kavuşmuş olacağız. Zira Batı dünyasından devşirdiğimiz değerleri, herhangi bir süzgece veya düzenlemeye tabi tutmadan olduğu gibi aktarmaya ve eğitim sahasına taşımaya çalışmamız, meselenin önemini kavramadığımız anlamına gelmektedir. O halde toplumumuza kendi bünyesine ait değerleri tanıtmakla işe başlamalıyız.

\section{Kaynakça}

Amundson, Kristen J. Teaching values and ethics an AASA critical issues report problems and solutions. Arlington: American Association of School Administrators Library and Congress, 1991.

Arslan, Ahmet. Felsefeye giriş. Ankara: Adres Yayınları, 12. bsk. 2009.

Arslan, Ahmed. İbni Haldun. İstanbul: İstanbul Bilgi Üniversitesi Yayınları, ts.

Aslan, Z. Şeyma \& Yaşar, Fatma T. "Yükselen değer kavramı üzerine eleştirel bir yaklaşım”. Değerler Eğitimi Dergisi, 1, 2007, 8-11.

Attas, Nakib. "İslâmi dünya görüşü: Genel bir çerçeve". İslâm ve Modernizim. İstanbul: İstanbul Büyükşehir Belediyesi Kültür İşleri Daire Bşkanlığı Yayınları, 1997.

Aytaç, Kemal. Avrupa eğitim tarihi. İstanbul: M.Ü. İlâhiyat Fakültesi. Yayınları, 1992.

Bauman, Zygmunt. Bireyselleşmiş toplum. trc. Yavuz Alogan, İstanbul: Ayrıntı Yayınları, 2005.

Blaut, J. M. Sömürgeciliğin dünya modeli. trc. Serbun Behçet. İstanbul: Dergâh Yayınları, 2015.

Bronowski, J. Science and human values. New York: Julian Messner Inc., 1956.

Cabirî, Muhammed Abid. Arap ahlâki akll. trc. Muhammed Çelik. İstanbul: Mana Yayınları, 2015.

Chittick, William. "Anlam arayışı”. Sûfi psikolojisi. ed. Kemal Sayar. İstanbul: Kapı Yayınları, 2016.

Comte, Auguste. Pozitivizm ilmihali. trc. Peyami Erman. İstanbul: M.E.B. Yayınları, 1952.

Debats, D.L. \& Bartelds, B.F. The structure of human values: a principal components analysis of the Roheach Value Survey (RVS), Debats, D. L. H. 
$\mathrm{M}$, Meaning in life: psychometric, clinical and phenomenological aspects, 1996.

Demircioğlu, İsmail H. Ve Tokdemir, Muhammed A. "Değerlerin oluşturulma sürecinde tarih eğitimi: Amaç, işlev ve içerik". Değerler Ĕgitimi Dergisi, 6/15, 69-88, Haziran 2008) 69-89.

Draz, Muhammed Abdullah. Din ve Allah İnancı. trc. Bekir Karlığa. İstanbul: Bir Yayınları, ts.

Elliott, Anthony \& Lemert, Charles. Yeni Bireycilik Küreselleşmenin Duygusal Bedelleri. Trc. Başak Kıcır, İstanbul: Sel Yayıncılık, 2011.

Erdoğan, Mustafa. "Sekülerizm, laiklik ve din". İslâmi Araştırmalar Dergisi, 8/3-4, 1995, 179-194.

Garaudy, Roger. İslam ve İnsanlığın Geleceği. trc. Cemal Aydın. İstanbul: Pınar Yayınları, 2015.

Güngör, Erol. Ahlâk psikolojisi ve sosyal ahlâk. İstanbul: Ötüken Yayınları, 1997.

Güngör, Erol. Değerler psikolojisi üzerinde araşttrmalar. İstanbul: Ötüken Yayınları, 1998.

Güngör, Erol. Türk kültürü ve milliyetçilik. İstanbul: Ötüken Yayınları, 1989.

Harbert, Kelsey. History of teaching and the value agenda. PHD thesis. Austuralia: James Cook University, 20009.

Harman, Willis. Küresel zihniyet değişimi, düşünme tarzında yeni çağ devrimi. trc. Muhammed Şeviker. İstanbul: İz Yayınları, 2000.

Hasan Hanefi, Muhammed Abid el-Cabiri, "Laiklik ve İslâm". İslâmi Araştırmalar Dergisi, 8/3-4 (1995).

Hume, David. A Treatise of human nature. London: Logmans Green and Co., 1898.

İzzetbegoviç, Aliya. Doğu Batı arasında İslam. trc. Salih Şaban. İstanbul: Yarın Yayınları, 2011.

Kirschenbaum, Howard. Enhance values and morality in schools and youth settings. Massachusetts: Allyn\&Bacon Company, 1995.

Krause, Uwe. "Avrupa Değerler Atlası: Avrupa Perspektifinden Değerler Tartı̧̧ması”. Değerler Eğitimi Eğitimde Farkllılk ve Katıllım Hakkl, der. A. Kaya, G. Vural, A. Aydın, trc. İlkay Südaş. İstanbul: İstanbul Bilgi Üniversitesi Yayınları, 2016, 3-24.

Kuçuradi, İoanna. İnsan ve değerleri. İstanbul: Yankı Yayınları, 1971.

Locke, John. Two treatises of gowernment. Dublin: Thomas Tegg, 1823.

Maclntyre, Alasdair. Homerik çağdan yirminci yüzyıla etik'in kısa tarihi. trc. Hakkı Hünler, Solmaz Zelyüt. İstanbul: Hünler, Paradigma Yayınları, 2001.

Marghant, J. R. V. \& Josep F. Harles. Latin dictionary. London: Gassell nad Company, ts.

Meriç, Cemil. Mağaradakiler. İstanbul: Ötüken Yayınları, 1978.

Turkish Academic Research Review - Türk Akademik Araştırmalar Dergisi

https://dergipark.org.tr/tr/pub/tarr 
Neşşâr, Ali Sami. İslam'da felsefi düşüncenin doğuşu. trc. Osman Tunç. İstanbul: İnsan Yayınları, 1999.

OECD, Future of education and skills 2030 concept. 2019.

Ortaylı, İlber. Avrupa ve Biz. İstanbul: İş Bankası Yayınları, 2007.

Öztaş, Sezai. "A Literary Genre in Value Education in History Courses: Poems", Journal of Education and Training Studies, 6/5, May 2018, 34-39.

Rousseau, Jean Jacques. The social contract and discourses. Indiana: Liberty Fund, Inc., 2010.

Schwartz, Shalom H. "Basic human values: An overview". https://www.researchgate.net/publication/237364051 (17.02.2021).

Schweitzer, Friedrich. "Dini Bireyleşme: Hoşgörü Eğitimine Karşı Yeniden Meydan Okumalar”. Sakarya Üniversitesi İlahiyat Fakültesi Dergisi,16, 2007.

Sennett, Richard. Kamusal insanın çöküşü. trc. Serpil Durak, Abdullah Yılmaz. İstanbul: Ayrıntı Yayınları, 2013.

Simmel, Georg. Bireysellik ve kültür. trc. Tuncay Birkan. İstanbul, Metis Yayınları, 2009.

Sorokin, Pitirim A. Bir bunalım çağında toplum felsefeleri. trc. Mete Tuncay. İstanbul: Göçebe Yayınları, 1997.

Spengler, Oswald. The decline of the west. trs. Charlies Francis Aykinson, New York: Alfred A. Knope, 1926.

Turgut, İhsan. Eğitim üzerine felsefi bir deneme. İzmir: Bilgehan Matbaası, 1991.

Whitehead, Alfred North. Düşüncelerin Serüvenleri. trc. Yusuf Kaplan, İstanbul: Külliyat Yayınları, 2008. 